\title{
Identification and Kinetic Properties of the Photosensitive Impurities and Defects in High-Purity Semi-Insulating Silicon Carbide
}

\author{
D. V. Savchenko, B. D. Shanina and E. N. Kalabukhova \\ V.E. Lashkaryov Institute of Semiconductor Physics, \\ National Academy of Science of Ukraine
}

Ukraine

\section{Introduction}

Semi-insulating (SI) silicon carbide substrates are required for high power microwave devices and circuits based on $\mathrm{SiC}$ and $\mathrm{GaN}$. SI properties of $\mathrm{SiC}$ can be achieved by introducing deep levels from either impurities or intrinsic defects into the material to compensate shallow donors and acceptors and pin the Fermi level near the middle of the bandgap. Intrinsic defects with deep levels are believed to be responsible for the SI properties of undoped material. Most of the intrinsic defects studied in SI 4H-SiC grown by physical vapour transport (PVT) and high temperature chemical vapour deposition (HTCVD), referred to as high purity semi-insulating (HPSI) material, have energies ranging from $0.85 \mathrm{eV}$ to $1.8 \mathrm{eV}$ below the conduction band (Müller et al., 2003; Son et al., 2004). However, not all of these defects are temperature stable and desirable for SI SiC. Among the defects, which are stable after annealing at $1600{ }^{\circ} \mathrm{C}-1800{ }^{\circ} \mathrm{C}$ and believed to be responsible for SI properties of HPSI 4H-SiC are the ID and SI-5 defects. ID defect with energy level of $1.79 \mathrm{eV}$ below the conduction band which occupies quasi-cubic (ID1) and hexagonal (ID2) lattice sites were observed in both HTCVD and PVT p-type HPSI wafers and identified as the carbon vacancy in the single positive charge state, $V_{C}^{+}$(Konovalov et al., 2003). The parameters of the ID1 and ID2 defects are coincided with those of E15 and E16 centers, respectively, which were observed in electron-irradiated p-type $4 \mathrm{H}-\mathrm{SiC}$ and originate from $\mathrm{V}_{\mathrm{C}}^{+}$at quasi-cubic (c) and hexagonal (h) lattice sites (a. Umeda et al., 2004; b. Umeda et al., 2004).

SI-5 defect with energy level of $1.2 \div 1.5 \mathrm{eV}$ below the conduction band $\left(\mathrm{E}_{\mathrm{C}}\right)$ is found to be a dominating defect among a series of other defects (SI1-SI9) observed in HTCVD and PVT HPSI $4 \mathrm{H}-\mathrm{SiC}$ substrates in the dark and under light illumination with different photon energies (Son et al. 2004). The HEI4 center with the g-values similar to those found for SI-5 defect was observed in electron irradiated n-type $4 \mathrm{H}-\mathrm{SiC}$ samples but with the concentration higher than that in HPSI samples which was sufficient to observe the hyperfine (HF) structure of the defect (a. Umeda et al., 2006). As a result, based on the analysis of the HF structures of ${ }^{29} \mathrm{Si}$ and ${ }^{13} \mathrm{C}$ and first principles calculations, the SI-5 center was identified to be 
originated from the negatively charged carbon antisite-vacancy $(\mathrm{AV})$ pair $\left(\mathrm{C}_{\mathrm{Si}} \mathrm{V}_{\mathrm{C}}^{-}\right)$ (b. Umeda et al., 2006). The energy level of the SI-5 center obtained from the photo-EPR studies of the electron irradiated n-type $4 \mathrm{H}-\mathrm{SiC}$ samples amounts to $1.1 \mathrm{eV}$ below the conduction band and coincides with the ionization levels $\left(E_{C}-1.0 \mathrm{eV}\right.$ and $\left.E_{C}-0.9 \mathrm{eV}\right)$ calculated from the first principles for the $(0 \mid-)$ and $(-\mid 2-)$ charge states of the $\mathrm{C}_{\mathrm{Si}} \mathrm{V}_{\mathrm{C}}$, respectively (Bockstedte et al., 2006). According to theory the Fermi level $\mathrm{E}_{\mathrm{F}}$ is pinned at $\sim \mathrm{E}_{\mathrm{C}}-1.1 \mathrm{eV}$ or lower due to $\mathrm{C}_{\mathrm{Si}} \mathrm{V}_{\mathrm{C}}$ in $\mathrm{SiC}$. Thus, the single vacancies as well as the carbon $\mathrm{AV}$ pairs are found to be the dominant defects responsible for the SI property of SiC.

The presented review indicates that the investigation of the SI SiC material mainly was focused on the identification of the intrinsic defects responsible for the SI properties of SiC. At the same time, investigation of the role, which they play in the trapping, recombination, and ionization of non-equilibrium charge carriers, processes of paramount importance for semiconducting materials, has not received proper attention. HPSI $4 \mathrm{H}-\mathrm{SiC}$ samples have a specific feature of the so-called persistent relaxation (PR) of the photo-response and persistent photoconductivity (PPC), which originate from a very long (over $30 \mathrm{~h}$ ) lowtemperature lifetime of photo-carriers trapped into defect and impurity levels (Kalabukhova et al., 2006).

In this chapter we present the results of identification of the intrinsic defects observed in EPR spectrum of HPSI $4 \mathrm{H}$ and $6 \mathrm{H}-\mathrm{SiC}$ wafers in the dark and under photo-excitation and investigation of the PR and PPC which form in HPSI $4 \mathrm{H}-\mathrm{SiC}$ samples at low temperatures after termination of photo-excitation.

The existence of very long lifetime of photo-carriers (PR of the photo-response) in semiconductors is reported since the 1930s (Sheinkman \& Shik, 1976). The phenomenon of the PPC has been observed for a wide set of binary (Queisser \& Theodorou, 1986; Dissanayake, et al., 1991; Evwaraye et al., 1995) and amorphous semiconductor materials (Kakalios \& Fritzsche, 1984).

The main specifications of PPC are the following: 1) the type of semiconductor and it's state (mono- or poly-crystal, or amorphous, or powder) is not important; 2) the wavelength of photo-excitation does not mean; 3 ) the photo-response time has a temperature dependence proportional to $\exp \left(\mathrm{E}_{\mathrm{rec}} / \mathrm{kT}\right)$, where $\mathrm{E}_{\text {rec }}$ is the recombination barrier, which depends on a time; 4) residual photoconductivity can achieve a large value $\sigma_{\mathrm{PPC}}>>\sigma_{0}$, where $\sigma_{0}$ is a conductivity before photo-excitation. Two main models have been proposed for the explanation of the PPC. In the first model, the reason of PPC existence is a significant concentration of traps, which serve as the recombination centres for electrons and holes and have enough high activation energy for ionization (Litton \& Reynolds, 1964). The second model is the so called a 'barrier model', which supposes the space separation of photocarriers due to an appearance of the electrical barriers, which are potential barriers for the recombination of carriers. Macroscopic potential barriers may arise at surfaces, interfaces, junctions, around doping inhomogeneities. Microscopic barriers against recombination may arise due to impurity atoms with large lattice relaxations (Lang \& Logan, 1977; Dissanayake \& Jiang, 1992). The second model was considered in (Shik A.Ya., 1976; Ryvkin \& Shlimak, 1973) as the main mechanism of PPC in CdS. The height of the barriers was determined to be equal to $10^{5} \mathrm{~V} / \mathrm{cm}$.

To distinguish between the models responsible for the PR and PPC in HPSI 4H-SiC we have studied kinetic properties of the photosensitive paramagnetic impurities (nitrogen and boron centers) and deep defects observed in HPSI $4 \mathrm{H} \mathrm{SiC}$, using EPR, photo EPR methods 
and optical admittance spectroscopy. It was expected that in the case of 'barrier model' electrostatic potential fluctuations will cause the noticeable shift of the g-factor of nitrogen donor centers with respect to that measured in the dark or broadening of their spectral lines as long as $4 \mathrm{HSiC}$ does not have the center of inversion symmetry. Otherwise, we have to reject this model and consider the role played in PR and PPC by deep traps.

\section{Samples and experimental technique}

The nature of the intrinsic defects in HPSI $4 \mathrm{H}$ and $6 \mathrm{H}-\mathrm{SiC}$ was studied on the samples grown up by the PVT method at the Cree Research Inc. and Bandgap Technologies Inc., respectively, by EPR and photo-EPR methods. The nature of PR of the photo-response and of PPC in HPSI $4 \mathrm{H}-\mathrm{SiC}$ material was studied on the samples grown by PVT method at the Cree Research Inc. by photo-EPR and optical admittance spectroscopy. The HPSI material was purposefully undoped $\mathrm{SiC}$ with a residual impurity concentration of the order of $10^{15} \mathrm{~cm}^{-3}$, which has a high room-temperature electrical resistivity (on the order of $10^{10} \Omega \cdot \mathrm{cm}$ ). Before carrying out experiments, the samples were annealed in an inert atmosphere at $\mathrm{T}=1800{ }^{\circ} \mathrm{C}$ to remove surface intrinsic defects which are known to be always present in a SI SiC material before its annealing and characterized by an EPR signal with isotropic g-factor $\mathrm{g}_{\|}=\mathrm{g}_{\perp}=2.0025$ (Macfarlane \& Zvanut, 1999; Kalabukhova et al., 2001).

A study of the temperature dependence of charge carrier concentration performed on the same HPSI $4 \mathrm{H}-\mathrm{SiC}$ samples on which the EPR measurements were carried out revealed that the samples were n-type, and that the Fermi level was localized in the upper half of the band gap. The activation energy, derived from the slope of the dependence of charge carrier concentration on $1 / \mathrm{T}$, turned out to be $1.1 \mathrm{eV}$. The charge carrier concentration determined at the highest temperature of the experiment was about $1 \times 10^{15} \mathrm{~cm}^{-3}$ (Kalabukhova et al., 2004).

The EPR and photo-EPR spectra were measured in an X-band (9 GHz) and Q-band (37 GHz) EPR spectrometers in the temperature range of $4.2 \mathrm{~K}-140 \mathrm{~K}$. Photo-excitation of samples by interband light was provided by a $250-\mathrm{W}$ high-pressure mercury vapor lamp equipped with interference filters for wavelengths from $365 \mathrm{~nm}$ to $380 \mathrm{~nm}$. To illuminate a sample with impurity light, a 100-W xenon and halogen incandescent lamps were used in combination with either an UM-2 prism monochromator or the interference or glass filters, which enabled us to carry out photo experiments in the wavelength range from $380 \mathrm{~nm}$ to $1000 \mathrm{~nm}$. Light focused by a short-focus doubleconvex quartz lens was coupled into the resonator through a light guide, with the sample of about $1.7 \times 4 \mathrm{~mm}^{2}$ in size fixed to its end face oriented such that the $c$ axis of the crystal was perpendicular to the direction of the external magnetic field. The thickness of the illuminated sample was about $35 \mu \mathrm{m}$, which was thin enough for the light to illuminate the total sample.

The PPC data obtained by optical admittance spectroscopy at $\mathrm{T}=300 \mathrm{~K}$ were taken from (Kalabukhova et al., 2006). The technique employed in optical admittance spectroscopy measurements was described in considerable detail in (Evwaraye et al., 1995).

The EPR spectra were simulated with the help of an Easyspin toolbox (Stoll \& Schweiger, 2005). The EPR lineshape was Gaussian. The determination error of the g-factor was \pm 0.0002 . The determination error for the defect and impurity energy levels was approximately $\pm 0.06 \mathrm{eV}$. 


\section{Identification of the photosensitive impurities and defects in HPSI SiC}

\subsection{Hydrogenated carbon vacancy in $\mathrm{HPSI} 4 \mathrm{H}-\mathrm{SiC}$}

Fig. 1 presents a typical EPR spectrum of the HPSI $4 \mathrm{H}-\mathrm{SiC}$ samples under study annealed at $\mathrm{T}=1800^{\circ} \mathrm{C}$, which were measured in the dark and under excitation with the different photon energies at $\mathrm{T}=77 \mathrm{~K}$ when magnetic field $\mathbf{B}_{0}$ is parallel to the $\mathbf{c}$-axis.
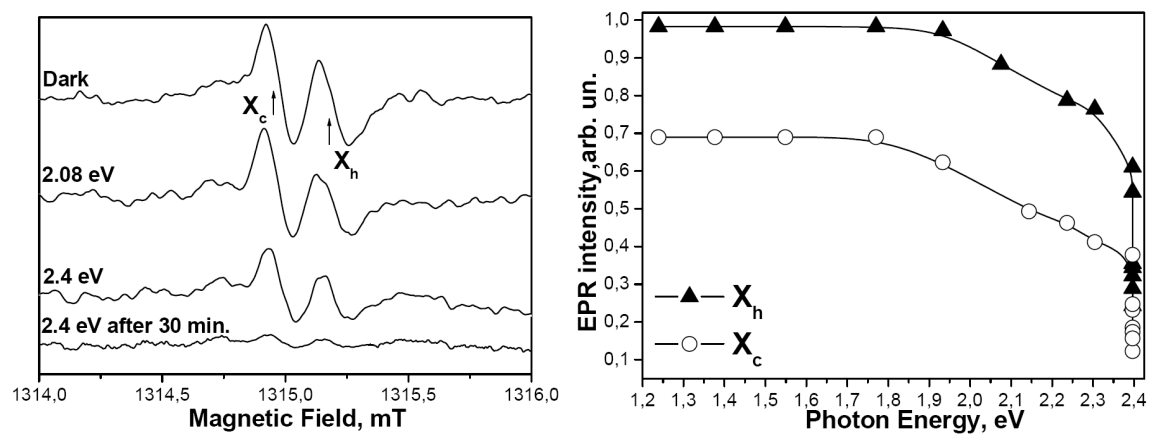

Fig. 1. Spectral dependence of the Q-band photo-EPR spectra of the X-defect measured in HPSI $4 \mathrm{H}-\mathrm{SiC}$ at $\mathrm{T}=77 \mathrm{~K}$. B $\mathbf{B}_{0}|| \mathbf{c}$. After (b. Kalabukhova et al., 2006).

The spectrum obtained in the dark reveals two EPR signals with an intensity ratio of 1:1.6 deriving from a thermally stable $X$ defect with $S=1 / 2$ which occupies the quasi-cubic $\left(X_{c}\right)$ and hexagonal $\left(\mathrm{X}_{\mathrm{h}}\right)$ positions in the $4 \mathrm{H}-\mathrm{SiC}$ lattice. At $77 \mathrm{~K}$, the EPR lines of $\mathrm{X}_{\mathrm{h}}$ and $\mathrm{X}_{\mathrm{c}}$ are both characterized by axial g-tensors: $\mathrm{g}_{\|}=2.0025, \mathrm{~g}_{\perp}=2.0044$ and $\mathrm{g}_{\|}=2.0028, \mathrm{~g}_{\perp}=2.0043$, respectively (Kalabukhova et al., 2004).

The energy level of the X-defect was determined from the spectral dependences of the intensities of the $X$ defect EPR lines. As was shown in Fig. 1, the intensity of the X-defect photo-EPR lines remains constant until the photon energy hv reaches to $1.90 \mathrm{eV}$. Above that photon energy, the intensity decreases. With a threshold photon energy of hv $=1.90 \mathrm{eV}$ for the $\mathrm{X}_{\mathrm{h}}$ defect the energy level of the $\mathrm{X}_{\mathrm{h}}$ defect can be determined as $\Delta \mathrm{E}=\mathrm{E}_{\mathrm{C}}-1.26 \mathrm{eV}$ and for $\mathrm{X}_{\mathrm{c}}$ as $\Delta \mathrm{E}=\mathrm{E}_{\mathrm{C}}-1.36 \mathrm{eV}$. When the photon energy approaches $\mathrm{h} v=2.4 \mathrm{eV}$ the EPR signals due to the $X$-defect gradually vanished. The transition of the single $X_{c} E P R$ line into six lines is observed at the temperature below $40 \mathrm{~K}$, showing that the symmetry of the EPR spectrum for the defect residing on a c site is lowered from axial $C_{3 v}$ to $C_{1 h}$, while the axial symmetry of the EPR spectrum due to the $\mathrm{X}$-defect residing on the $\mathrm{h}$ site remains.

The ligand HF structure of the $X_{h}$ and $X_{c}$ defect was analyzed at $X$-band frequency. As was seen from Fig. 2, at $X$-band frequency, the $X_{h}$ and $X_{c}$ EPR signals are superimposed and the EPR spectrum consists of a single line with a slightly asymmetric line shape at $\mathbf{B}_{0} \| \mathbf{c}$. Besides the strong central line, six weaker satellite lines (labeled 1 to 6 ) belonging to the $X_{h}$, and $X_{c}$ defect are found symmetrically around the central line. The HF interaction constants determined from comprehensive analysis of the complete angular dependence of all satellites are in excellent agreement with those found for the Si-nearest neighbors of the carbon vacancy $\mathrm{V}_{\mathrm{C}}^{+/ 0}$, both at the $\mathrm{c}$ and $\mathrm{h}$ lattice sites known as EI5 and EI6 (a. Umeda et al., 2004; b. Umeda et al., 2004) or ID and ID2 (Konovalov et al., 2003) centers. The results of this analysis are summarized in Table 1. 


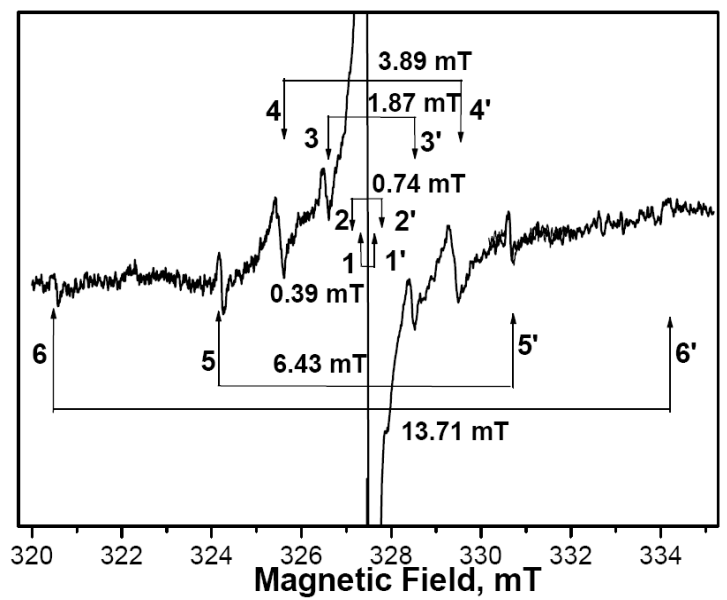

Fig. 2. X-band EPR spectrum of the X-defect measured at $77 \mathrm{~K}$. $\mathbf{B}_{0} \| \mathbf{c}$. After (b. Kalabukhova et al., 2006).

\begin{tabular}{|c|c|c|c|c|c|}
\hline $\begin{array}{l}\text { Satellite } \\
\text { line } \\
\text { number1) }\end{array}$ & $\mathbf{A}_{\|}, \mathrm{mT}$ & $\mathrm{A}_{\perp}, \mathrm{mT}$ & $\begin{array}{c}\text { Relative intensities } \\
\text { and assignments of } \\
X_{\mathrm{c}} / \mathrm{X}_{\mathrm{h}} \text { ligand } \\
\text { structure }\end{array}$ & $\begin{array}{c}\text { Assignments } \\
\text { of ID1/ID2 } \\
\text { ligand } \\
\text { structure }\end{array}$ & $\begin{array}{c}\text { Assignments } \\
\text { of E15/E16 } \\
\text { ligand } \\
\text { structure }\end{array}$ \\
\hline$(5-5 ')$ & 6.43 & 4.46 & $\begin{array}{c}\mathrm{X}_{\mathrm{C}}-1: 0.060 \\
1 \times{ }^{29} \mathrm{Si}\end{array}$ & $\begin{array}{l}\text { ID1-1: } \\
1 \times{ }^{29} \mathrm{Si}\end{array}$ & $\begin{array}{l}\text { E15-1: } \\
1 \times 29 S i\end{array}$ \\
\hline$\overline{\left(4-4^{\prime}\right)}$ & 3.89 & 4.08 & $\begin{array}{c}\mathrm{X}_{\mathrm{C}}-2: 0.146 \\
3 \times{ }^{29} \mathrm{Si}\end{array}$ & $\begin{array}{l}\text { ID1-2: } \\
3 \times{ }^{29} \mathrm{Si}\end{array}$ & $\begin{array}{l}\text { E15-2: } \\
3 \times{ }^{29} \mathrm{Si}\end{array}$ \\
\hline$\left(1-1^{\prime}\right)$ & 0.39 & 0.34 & $\begin{array}{c}\mathrm{X}_{\mathrm{C}}-3: 0.543 \\
12 \times{ }^{13} \mathrm{C}+8 \times{ }^{29} \mathrm{Si}\end{array}$ & $\begin{array}{l}\text { ID1-3: } \\
12 \times 13 \mathrm{C}\end{array}$ & $\begin{array}{l}\text { E15( }\left(^{*}\right)-3: \\
5-11 \times{ }^{13} \mathrm{C} \\
+3 \times{ }^{29} \mathrm{Si}\end{array}$ \\
\hline$\left(6-6^{\prime}\right)$ & 13.71 & 9.52 & $\begin{array}{c}\mathrm{X}_{\mathrm{h}}-1: 0.062 \\
1 \times{ }^{29} \mathrm{Si}\end{array}$ & $\begin{array}{l}\text { ID2-1: } \\
1 \times{ }^{29} \mathrm{Si}\end{array}$ & $\begin{array}{c}\text { E16-1: } \\
1 \times{ }^{29} \mathrm{Si}\end{array}$ \\
\hline$\left(3-3^{\prime}\right)$ & 1.87 & 2.76 & $\begin{array}{c}\mathrm{X}_{\mathrm{h}}-2: 0.146 \\
3 \times{ }^{29} \mathrm{Si}\end{array}$ & $\begin{array}{l}\text { ID2-2: } \\
3 \times{ }^{29} \mathrm{Si}\end{array}$ & $\begin{array}{c}\text { E16-2: } \\
3 \times{ }^{29} \mathrm{Si}\end{array}$ \\
\hline$\left(2-2^{\prime}\right)$ & 0.74 & 0.66 & $\begin{array}{c}X_{h}-3: 0.156 \\
3 \times{ }^{29} S i\end{array}$ & $\begin{array}{l}\text { ID2-3: } \\
3 \times{ }^{29} \mathrm{Si}\end{array}$ & $\begin{array}{l}\text { E16-3: } \\
3 \times{ }^{29} \mathrm{Si}\end{array}$ \\
\hline
\end{tabular}

Table 1. EPR parameters of the $X_{c}$ and $X_{h}$ defects with $S=1 / 2$ in HPSI $4 \mathrm{H}-\mathrm{SiC}$ samples measured at $\mathrm{T}=77 \mathrm{~K} . \mathrm{A}_{\|}$and $\mathrm{A}_{\perp}$ are the HF splitting as determined from angular dependent EPR measurements. The number of magnetic nuclei determined from the relative intensities of the HF satellites is given after (Kalabukhova et al., 2006) for $X_{c} / X_{h}$, after (Konovalov et al., 2003) for ID1/ID2 and after (a, b. Umeda, et al., 2004; Bockstedte et al., 2003) for E15/E16 centers residing $\mathrm{c} / \mathrm{h}$ positions. ${ }^{1)}$ The lines are labeled after Fig. $2 .\left(^{*}\right)$ The number of magnetic nuclei was determined by pulsed ENDOR (b. Umeda et al., 2004).

However, there are significant discrepancies in the intensity ratio of line (1-1') with HF splitting of $A_{\|}=0.39 \mathrm{mT}$ and $A_{\perp}=0.34 \mathrm{mT}$ in all four references given in Table 1. Since all other intensity ratios coincide within experimental error, the mistakes in the measurements 
can be excluded. Thus varying sample preparations might be responsible, and therefore probably slightly different defects might occur. Nevertheless, the disturbance is rather small and in particular cannot be explained by another charge state of the carbon vacancy, e.g. $\mathrm{V}_{\mathrm{C}}^{-}$ is known to have distinctly different HF interaction constants (Umeda et al., 2005).

Since the HF splitting is the same in all cases, but the number of nuclei involved is different, one has to discuss a common additional rather small disturbance of the carbon vacancies. The twofold HF splitting suggests that a nucleus with nuclear spin $I=1 / 2$ and high (probably $100 \%$ ) natural abundance is involved. There are only a few plausible nuclei in question. The most probable candidate is hydrogen, which e.g. also in silicon provokes a small disturbance of defects, introduced by sample preparation and only hardly observable with EPR (Langhanki et al., 2001).

This conclusion is supported by the ionization energy of X-defect which is close to that calculated for $\mathrm{V}_{\mathrm{C}}$ with adjacent hydrogen $\left(\mathrm{V}_{\mathrm{C}}+\mathrm{H}\right)$ (Aradi et al., 2001; Gali et al., 2003) and has significant higher ionization energy than that known for EI5/EI6 center, see Table 2.

\begin{tabular}{|l|l|l|}
\hline Experimental $\mathrm{E}_{\mathrm{V}}-\mathrm{E}_{\mathrm{i}}$ & Theory (A. Gali et al., 2003) & Model \\
\hline $1.47 \mathrm{eV}$ (Son et al., 2002) & $1.57 \mathrm{eV}$ & $\mathrm{V}_{\mathrm{C}}+/ 0$ acceptor \\
\hline $\begin{array}{l}1.90 \mathrm{eV}, 2.00 \mathrm{eV} \text { (b. Kalabukhova et } \\
\text { al., 2006) }\end{array}$ & $2.05 \mathrm{eV}$ & $\left(\mathrm{V}_{\mathrm{C}}+\mathrm{H}\right)^{0 /-}$ donor \\
\hline
\end{tabular}

Table 2. Ionization energies $\left(\mathrm{E}_{\mathrm{i}}\right)$ of the isolated carbon vacancy $\mathrm{V}_{\mathrm{C}}$ and hydrogenated carbon vacancies $\left(V_{C}+H\right)$ in respect to the valence band $\left(E_{v}\right)$ from experiment and theory.

As was seen from Table 2, the energy level of the $\mathrm{V}_{\mathrm{C}}^{+/ 0}$ in contrast to the $\mathrm{X}$-defect is pinned in the lower half of the band gap and shows acceptor-like behavior. Therefore, the X-defect which shows the donor-like behavior was assigned to the hydrogenated carbon vacancy $\left(\mathrm{V}_{\mathrm{C}}+\mathrm{H}\right)^{0 /-}$ which occupies the $\mathrm{c}$ and $\mathrm{h}$ positions in the $4 \mathrm{H}-\mathrm{SiC}$ lattice (Kalabukhova et al., 2006).

In accordance with calculations performed in (Aradi et al., 2001; Gali et al., 2003), the most stable configuration of the $\left(\mathrm{V}_{\mathrm{C}}+\mathrm{H}\right)^{0 /-}$ is that where hydrogen is built in bond-bridging between two Si-ligands of $\mathrm{V}_{\mathrm{C}}$ as was shown in Fig. 3.
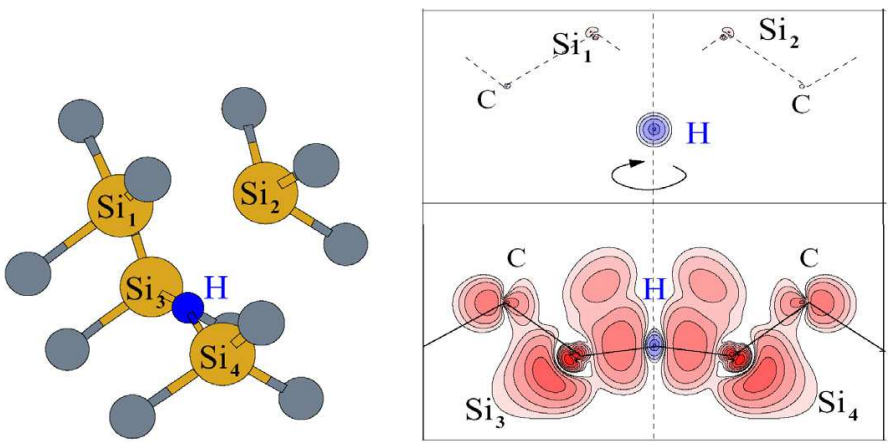

Fig. 3. Calculated ground state geometry and corresponding spin-density (in two perpendicular planes) of the hydrogenated carbon vacancy $\left(\mathrm{V}_{\mathrm{C}}+\mathrm{H}\right)$ at the quasi-cubic site in 4H-SiC. After (b. Kalabukhova et al., 2006). 
On the other hand accounting the $C_{3 v}$ symmetry of the high-temperature $(T=77 \mathrm{~K}) \mathrm{EPR}$ spectrum of $\mathrm{X}_{\mathrm{C}}$ defect caused by a dynamic Jahn-Teller effect the motional averaged configuration with the $\mathrm{H}$-atom in the center of three ligands $\mathrm{Si}_{3}, \mathrm{Si}_{4}$ and $\mathrm{Si}_{2}$ has been proposed in (b. Kalabukhova et al., 2006) which provides nearly isotropic HF parameters for $\mathrm{X}_{\mathrm{C}}$ defect and are in reasonable agreement with the experimental values of the HF splitting given in Table 1.

According to our analysis, in the present sample about $20 \%$ of the carbon vacancies would be contaminated with hydrogen. This is compatible with the lower signal-to-noise ratio observed in our study compared to that in the literature.

The proposed model for $X$ defect is in agreement with the temperature dependent Hall effect measurements indicating that the Fermi level is pinned in the upper half of the band gap at an energy close to that of the X-defect, suggesting it is donor-like.

\subsection{Photosensitive impurities in HPSI $4 \mathrm{H}-\mathrm{SiC}$}

Fig. 4 shows the EPR spectrum of the HPSI $4 \mathrm{H}-\mathrm{SiC}$ samples measured in the dark and under interband light at $T=77 \mathrm{~K}$. The EPR spectrum consists of a single line due to the $X_{h}$ and $X_{c}$ defects which EPR lines are superimposed when magnetic field $\mathbf{B}_{0}$ is perpendicular to the $\mathbf{c}-$ axis.

The EPR spectra of nitrogen and boron are not seen in the dark, which suggests that shallow donor and acceptor centers of the nitrogen and boron impurities reside in the ionized state because of the mutual compensation of their charge or partial compensation by deep-level defects. In our particular case, such a defect is the $\mathrm{X}$ defect lying 1.36-1.26 eV below the conduction band bottom.

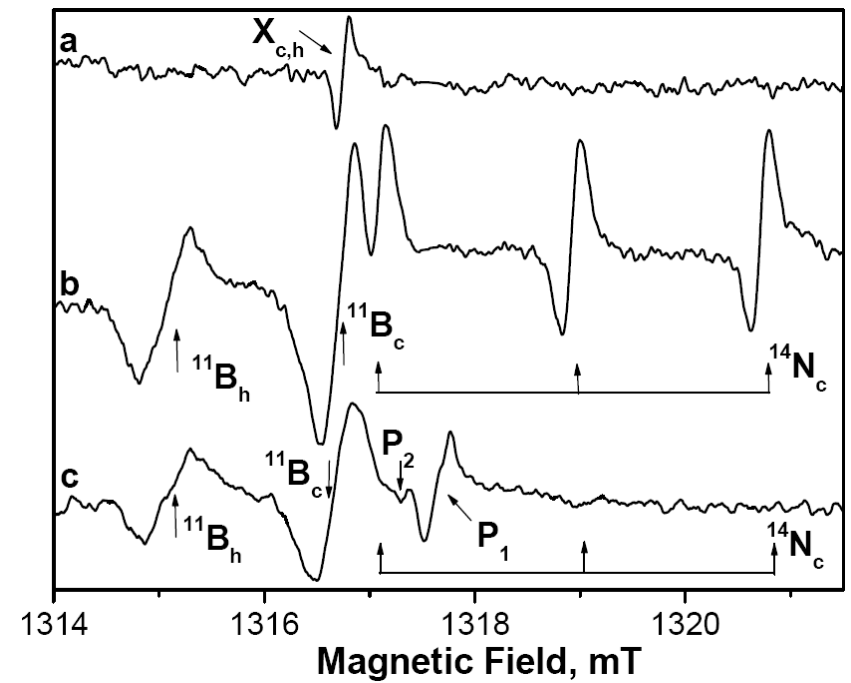

Fig. 4. Photo-response of the Q-band EPR spectrum in HPSI $4 \mathrm{H}-\mathrm{SiC}$ samples at $\mathrm{T}=77 \mathrm{~K}$ and $\mathbf{B}_{0} \perp \mathbf{c}$ : (a) - in the dark, (b) - excitation with interband light, and (c) - EPR spectrum measured in the dark $21 \mathrm{~h}$ after termination of photo-excitation. After (a. Savchenko et al., 2009). 
Illumination of the samples with interband light of wavelength $365 \mathrm{~nm}$ gives rise to trapping of non-equilibrium charge carriers into the donor and acceptor levels of nitrogen and boron, which generates in the EPR spectrum simultaneously a triplet of EPR lines due to nitrogen in the quasi-cubic position $\left(\mathrm{N}_{\mathrm{c}}\right)$ (Greulich-Weber, 1997) and two EPR signals of boron occupying quasi-cubic $\left(B_{c}\right)$ and hexagonal $\left(B_{h}\right)$ positions of $C_{3 v}$ symmetry above $50 \mathrm{~K}$ (Greulich-Weber, et al., 1998). At the same time trapping of nonequilibrium charge carriers into the levels of the $X$ defect changes its charge state and initiates its transition to the nonparamagnetic state.

As will be shown in Section 4.1, the EPR signal due to nitrogen in hexagonal position $\left(\mathrm{N}_{\mathrm{h}}\right)$ was observed in EPR spectrum of the HPSI $4 \mathrm{H}-\mathrm{SiC}$ at $50 \mathrm{~K}$ under illumination with interband light.

The EPR parameters of the nitrogen and boron centers measured in HPSI $4 \mathrm{H}-\mathrm{SiC}$ in the presence of photo-excitation are listed in Table 3. In addition, the energy ionizations of the nitrogen and boron centers are given in Table 3 after (Evwaraye et al., 1996) and (Sridhara et al., 1998), respectively.

\begin{tabular}{|c|c|c|c|c|}
\hline Impurity & $\mathrm{N}_{\mathrm{c}}$ & $\mathrm{N}_{\mathrm{h}}$ & $\mathrm{B}_{\mathrm{c}}$ & $\mathrm{B}_{\mathrm{h}}$ \\
\hline $\mathrm{g}_{\|}$ & 2.0043 & 2.0063 & 2.0063 & 2.0019 \\
\hline $\mathrm{g}_{\perp}$ & 2.0013 & 2.0006 & 2.0046 & 2.0070 \\
\hline $\mathrm{A}_{\|}, \mathrm{mT}$ & 1.82 & 0.10 & 0.20 & 0.20 \\
\hline $\mathrm{A}_{\perp}, \mathrm{mT}$ & 1.82 & 0.10 & 0.11 & 0.12 \\
\hline $\mathrm{E}_{\mathrm{C}}-\mathrm{E}_{\mathrm{i}}, \mathrm{eV}$ & 0.10 & 0.053 & \multicolumn{2}{|c|}{0.628} \\
\hline $\mathrm{E}_{\mathrm{V}}+\mathrm{E}_{\mathrm{i}}, \mathrm{eV}$ & \multicolumn{5}{|c|}{} & \multicolumn{2}{|c|}{} \\
\hline
\end{tabular}

Table 3. EPR parameters and energy ionizations of nitrogen $\left(\mathrm{N}_{c}\right.$ and $\left.\mathrm{N}_{h}\right)$ and boron $\left(\mathrm{B}_{\mathrm{c}}\right.$ and $\mathrm{B}_{\mathrm{h}}$ ) centers measured in HPSI $4 \mathrm{H}-\mathrm{SiC}$ under photo-excitation with interband light in the temperature interval from $50 \mathrm{~K}$ to $80 \mathrm{~K}$. $\mathrm{A}_{\|}$and $\mathrm{A}_{\perp}$ are the $\mathrm{HF}$ splitting.

Comparing the obtained data with the literature data has shown that there is no difference between g-tensor of nitrogen EPR spectrum measured in HPSI $4 \mathrm{H}-\mathrm{SiC}$ in the presence of the photo-excitation and in n-type $4 \mathrm{H} \mathrm{SiC}$ crystals with $\left(\mathrm{N}_{\mathrm{D}}-\mathrm{N}_{\mathrm{A}}\right)=10^{17}-10^{18} \mathrm{~cm}^{-3}$ measured in the dark (Kalabukhova et al., 2007).

Therefore one can exclude the presence of the electrical barriers in the HPSI 4H-SiC sample after its photo-excitation which may disturb the local environment of the donors and give rise to the shift of the g-factor of nitrogen EPR spectrum with respect to that observed in the dark (Kalabukhova et al., 1990).

It was found that the lifetime of the nonequilibrium charge carriers trapped into the donor and acceptor levels of nitrogen and boron is very large (on the order of $30 \mathrm{~h}$ and longer). This PR of the photo-response after termination of photo-excitation is accompanied by the PPC phenomenon (a. Kalabukhova et al., 2006).

Examining Fig. 4, we see that the EPR line intensities of nitrogen and boron signals decay very slowly after termination of the pump light. Within $21 \mathrm{~h}$ after switching off the light, the EPR signal intensities of boron, $B_{c}$ and $B_{h}$, are 0.4 and 0.7 of those under illumination, respectively, while the $\mathrm{N}_{c}$ EPR line intensity drops in this time to 0.07 of that observed with the light on. 


\subsection{Carbon antisite-vacancy pair $\mathrm{C}_{\mathrm{Si}} \mathrm{V}_{\mathrm{C}}$ and silicon vacancy in $\mathrm{HPSI} 4 \mathrm{H}-\mathrm{SiC}$}

As evident from Fig. 4, when the EPR nitrogen triplet line intensities decay, EPR signals due to another defect center, labeled as the $P_{1}$ and $P_{2}$ defects, appear in the EPR spectrum. This suggests that electrons detrapping from the nitrogen level become trapped into the level of the $\mathrm{P}_{1}$ and $\mathrm{P}_{2}$ centers. On the other hand, as can be seen in Fig. 5 , the transformation of the $\mathrm{P}_{1}$ and $\mathrm{P}_{2}$ centers into an EPR-active charge state can be achieved by the photo-excitation of the HPSI 4H-SiC sample with a threshold photon energy of approximately $\mathrm{hv}=2.11 \mathrm{eV}$ (598 nm) making it possible to determine the position of the energy level of $\mathrm{P}_{1}$ and $\mathrm{P}_{2}$ defects as: $\Delta \mathrm{E}=\Delta \mathrm{E}_{\mathrm{g}}-2.11 \mathrm{eV}=\mathrm{E}_{\mathrm{C}}-1.15 \mathrm{eV}$ (Kalabukhova et al., 2004).

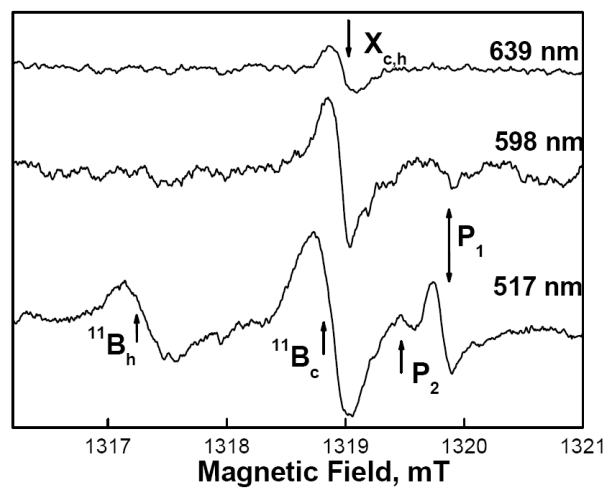

Fig. 5. Behavior of the EPR spectrum of HPSI $4 \mathrm{H}-\mathrm{SiC}$ sample measured at $37 \mathrm{GHz}$ and $77 \mathrm{~K}$ under illumination with the light of different photon energies. $\mathbf{B}_{0} \perp \mathbf{c}$. After (Kalabukhova et al., 2004).

The EPR line due to $\mathrm{P}_{1}$ defect has axially symmetric g-tensor $\left(\mathrm{g}_{\|}=2.0048, \mathrm{~g}_{\perp}=2.0030\right)$ but was too weak in intensity to be identified using its HF structure due to the small concentration of the defect, estimated to be about $5 \cdot 10^{14} \mathrm{~cm}^{-3}$. It should be noted that the second EPR line of small intensity with isotropic g-value $g=2.0037$, labeled $P_{2}$ defect, always appears in the EPR spectrum of HPSI $4 \mathrm{H}-\mathrm{SiC}$ along with the $\mathrm{P}_{1}$ defect signal having the axially symmetric g-tensor.

The high symmetry of the this line gave us argument to compare the symmetry, energy ionization and spin state of the $\mathrm{P}_{2}$ defect with electronic and structural properties of silicon vacancies calculated in (Torpo et al., 2001) which are generally have $T_{d}$ symmetry group and less frequently a lower symmetry like $C_{3 v}$. Among all possible configuration the silicon vacancy in the (3-) charge state can provide the characteristics (low spin state, $S=1 / 2$, energy ionization level of about $2.25 \mathrm{eV}$ above the valence band maximum) which are suitable for the $\mathrm{P}_{2}$ defect. Therefore, it was suggested that $\mathrm{P}_{2}$ defect is due to the $\mathrm{V}_{\mathrm{Si}}^{3-}$. But at the same time the EPR parameters of the $\mathrm{P}_{1}$ defect with axially symmetric g-tensor agree well with those of the SI-5 center observed in HPSI $4 \mathrm{H} \mathrm{SiC} \mathrm{(Son} \mathrm{et} \mathrm{al.,} \mathrm{2004)} \mathrm{and} \mathrm{in} \mathrm{electron}$ irradiated n-type $4 \mathrm{H} \mathrm{SiC} \mathrm{(a.} \mathrm{Umeda} \mathrm{et} \mathrm{al.,} \mathrm{2006)} \mathrm{at} 77 \mathrm{~K}$. In addition, energy position of the $\mathrm{P}_{1}$ defect coincides with that of SI-5 center which amounts to $1.1 \mathrm{eV}$ below the conduction band and coincides with the ionization levels $\left(E_{C}-1.0 \mathrm{eV}\right.$ and $\left.E_{C}-0.9 \mathrm{eV}\right)$ calculated from the first principles for the $(0 \mid-)$ and (- $\mid 2-)$ charge states of the carbon antisite-vacancy (AV) 
pair $\mathrm{C}_{\mathrm{Si}} \mathrm{V}_{\mathrm{C}}$, respectively (Bockstedte et al., 2006). Therefore, $\mathrm{C}_{\mathrm{Si}} \mathrm{V}_{\mathrm{C}}$ pair could be suggested as the most possible model for the $\mathrm{P}_{1}$ defect. This suggestion is supported by the fact that the transformation of $\mathrm{C}_{\mathrm{Si}} \mathrm{V}_{\mathrm{C}}$ from nonparamagnetic (-2) into paramagnetic (-1) state similar to the $\mathrm{P}_{1}$ defect is caused by capture of the electrons from nitrogen donors into the $\mathrm{C}_{\mathrm{Si}} \mathrm{V}_{\mathrm{C}}$ defect level under light illumination (b. Umeda et al., 2006).

It should be noted that the similar isotropic line with $\mathrm{g}=2.0037$, labeled as SI-11, has also been observed together with SI-5 defect signal in HPSI 4H-SiC in (Son et al., 2004; Carlsson P. et al., 2007) but was not assigned with the inequivalent position of the SI- 5 center due its small intensity. Theoretically predicted bistabillity between carbon $\mathrm{AV}$ complex $\mathrm{C}_{\mathrm{Si}} \mathrm{V}_{\mathrm{C}}$ and the isolated $\mathrm{Si}$ vacancy depending on the position of the Fermi level $\left(\mathrm{E}_{\mathrm{F}}\right)$ make it possible to suggest that this weak EPR line, with isotropic $\mathrm{g}=2.0037$ is due to the presence of small concentration of the $\mathrm{Si}$ vacancy which was predicted to be more stable in n-type than in ptype HPSI 4H-SiC samples (Rauls et al., 2003; b Bockstedte et al., 2003; Bockstedte et al., 2004). Spin-Hamiltonian parameters and energy levels of the thermally stable deep intrinsic defects with $\mathrm{S}=1 / 2$ measured in HPSI $4 \mathrm{H}-\mathrm{SiC}$ samples at $\mathrm{T}=77 \mathrm{~K}$ were listed in Table 4 .

\begin{tabular}{|c|c|c|c|c|}
\hline Defects & $\mathrm{P}_{1}$ & $\mathrm{P}_{2}$ & $\mathrm{X}_{\mathrm{C}}$ & $\mathrm{X}_{\mathrm{h}}$ \\
\hline $\mathrm{g}_{\|}$ & 2.0048 & 2.0037 & 2.0028 & 2.0025 \\
\hline $\mathrm{g}_{\perp}$ & 2.0030 & 2.0037 & 2.0043 & 2.0044 \\
\hline $\mathrm{E}_{\mathrm{C}}-\mathrm{E}_{\mathrm{i}}, \mathrm{eV}$ & 1.15 & 1.15 & 1.36 & 1.26 \\
\hline Model & $\mathrm{C}_{\mathrm{Si}} \mathrm{V}_{\mathrm{C}}^{0 /-}$ & $\mathrm{V}_{\mathrm{Si}}^{3-}$ & \multicolumn{2}{|c|}{$\left(\mathrm{V}_{\mathrm{C}}+\mathrm{H}\right)^{0 /-}$} \\
\hline
\end{tabular}

Table 4. Spin-Hamiltonian parameters and energy levels of the deep intrinsic defects with $\mathrm{S}=1 / 2$ measured in HPSI $4 \mathrm{H}-\mathrm{SiC}$ samples at $\mathrm{T}=77 \mathrm{~K}$ along with their identification.

\subsection{Carbon vacancy and carbon antisite-vacancy pair $\mathrm{C}_{\mathrm{Si}} \mathrm{V}_{\mathrm{C}}$ in $\mathrm{HPSI} 6 \mathrm{H}-\mathrm{SiC}$}

As was already mentioned above, most of the study of intrinsic defects in SI SiC has been made on the $4 \mathrm{H}$ polytype due to its relatively wide availability but very little reported on SI $6 \mathrm{H}-\mathrm{SiC}$. Fig. 6 shows the EPR spectrum observed in annealed HPSI $6 \mathrm{H}-\mathrm{SiC}$ sample at $77 \mathrm{~K}$ in the dark and under illumination with the light of different photon energy. As seen from Fig. $6 \mathrm{HPSI} 6 \mathrm{H}-\mathrm{SiC}$ reveals a series of photosensitive paramagnetic centers including boron $\left(\mathrm{B}_{\mathrm{c} 1, \mathrm{c} 2}\right.$ and $\left.\mathrm{B}_{\mathrm{h}}\right)$, nitrogen $\left(\mathrm{N}_{\mathrm{c} 1, \mathrm{c} 2}\right)$ and two thermally stable deep intrinsic defects labeled as $\mathrm{XX}$ and PP (Savchenko et al., 2006; Savchenko \& Kalabukhova, 2009). The EPR parameters of the nitrogen and boron centers measured in HPSI $6 \mathrm{H}-\mathrm{SiC}$ in the presence of photo-excitation are coincided with those measured in n-type $6 \mathrm{H} \mathrm{SiC} \mathrm{(b.} \mathrm{Savchenko} \mathrm{et} \mathrm{al.,} \mathrm{2009)} \mathrm{and} \mathrm{p-type}$ $6 \mathrm{H} \mathrm{SiC} \mathrm{(Greulich-Weber} \mathrm{et} \mathrm{al.,} \mathrm{1998)} \mathrm{in} \mathrm{the} \mathrm{dark} \mathrm{and} \mathrm{are} \mathrm{listed} \mathrm{in} \mathrm{Table} \mathrm{5.} \mathrm{The} \mathrm{notation} \mathrm{for}$ the XX and PP defects was selected by analogy with that adopted for two thermally stable intrinsic defects $\mathrm{X}$ and $\mathrm{P}$, which are observed in HPSI $4 \mathrm{H}-\mathrm{SiC}$ with very similar EPR parameters.

The photo EPR data placed the energy level of the defects in the region $1.24 \div 1.29 \mathrm{eV}$ above the valence band (Savchenko \& Kalabukhova, 2009). The EPR parameters and symmetry features of the $X X$ defect which substitutes three inequivalent positions $\left(X X_{h}, X_{c 1}\right.$ and $\left.X X_{c 2}\right)$ in the $6 \mathrm{H}-\mathrm{SiC}$ lattice was found to be similar to those of the $\mathrm{Ky} 3(\mathrm{~h}), \mathrm{Ky} 1(\mathrm{c})$ and $\mathrm{Ky} 2(\mathrm{c})$ defect observed in p-type electron irradiated $6 \mathrm{H}-\mathrm{SiC}$ samples and assigned to the carbon vacancy in the single positive charge state $\mathrm{V}_{\mathrm{C}}^{+}$at three inequivalent positions (Bratus et al., 2005). 


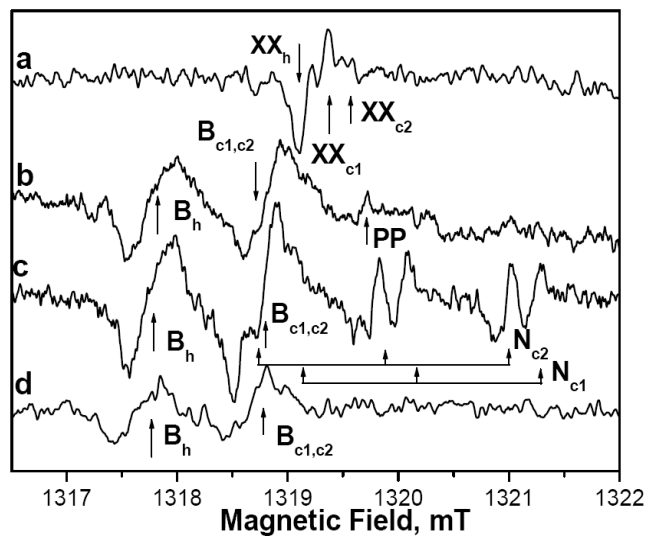

Fig. 6. Q-band EPR spectrum measured in HPSI 6H-SiC sample in the dark (a) and under illumination with the light of different photon energies: (b) $-2.79 \mathrm{eV}$; (c) $-3.06 \mathrm{eV}$, (d) - EPR spectrum measured in the dark $17 \mathrm{~h}$ after termination of photo-excitation. $\mathbf{B}_{0} \perp \mathbf{c}$. $\mathrm{T}=77 \mathrm{~K}$. After (Savchenko \& Kalabukhova, 2009).

\begin{tabular}{|c|c|c|c|c|c|}
\hline Impurity & $\mathrm{N}_{\mathrm{c} 1}$ & $\mathrm{~N}_{\mathrm{c} 2}$ & $\mathrm{~B}_{\mathrm{c} 1}$ & $\mathrm{~B}_{\mathrm{c} 2}$ & $\mathrm{~B}_{\mathrm{h}}$ \\
\hline $\mathrm{g}_{\|}$ & 2.0040 & 2.0037 & 2.0055 & 2.0062 & 2.0020 \\
\hline $\mathrm{g}_{\perp}$ & 2.0026 & 2.0030 & 2.0045 & 2.0045 & 2.0068 \\
\hline $\mathrm{A}_{\|}, \mathrm{mT}$ & 1.20 & 1.19 & 0.22 & 0.19 & 0.19 \\
\hline $\mathrm{A}_{\perp}, \mathrm{mT}$ & 1.20 & 1.19 & 0.13 & 0.12 & 0.15 \\
\hline$E_{C}-E_{i}, e V$ & 0.138 & 0.142 & & & \\
\hline $\mathrm{E}_{\mathrm{V}}+\mathrm{E}_{\mathrm{i}}, \mathrm{eV}$ & & & \multicolumn{2}{|c|}{$0.31-0.38$} & 0.27 \\
\hline
\end{tabular}

Table 5. EPR parameters of nitrogen and boron centers measured in HPSI $6 \mathrm{H}$-SiC under photo-excitation with interband light in the temperature interval from $50 \mathrm{~K}$ to $80 \mathrm{~K}$. The energy ionizations of the nitrogen and boron centers are given after (Suttrop et al., 1992) and (Evwaraye et al., 1997), respectively. $\mathrm{A}_{\|}$and $\mathrm{A}_{\perp}$ are the HF splitting

Therefore, $\mathrm{XX}$ defect was also attributed to the carbon vacancy in the single positive charge state $\mathrm{V}_{\mathrm{C}}^{0 /+}$ that substitutes three inequivalent positions. The spin-Hamiltonian parameters of the thermally stable deep intrinsic defects observed in HPSI $6 \mathrm{H}-\mathrm{SiC}$ samples at $\mathrm{T}=77 \mathrm{~K}$ along with their identification and energy levels are summarized in Table 6.

\begin{tabular}{|c|c|c|c|c|c|c|c|}
\hline Sample & \multicolumn{3}{|c|}{ HPSI 6H-SiC } & \multicolumn{3}{c|}{ e-irradiated p-type 6H-SiC } & HPSI 6H-SiC \\
\hline Defects & $\mathrm{XX}_{\mathrm{h}}$ & $\mathrm{XX}_{\mathrm{c} 1}$ & $\mathrm{XX}_{\mathrm{c} 2}$ & $\mathrm{Ky} 3(\mathrm{~h})$ & $\mathrm{Ky} 2(\mathrm{c})$ & $\mathrm{Ky} 1(\mathrm{c})$ & $\mathrm{PP}$ \\
\hline $\mathrm{g}_{\|}$ & 2.0024 & 2.0027 & 2.0035 & 2.0025 & 2.0028 & 2.0036 & 2.0047 \\
\hline $\mathrm{g}_{\perp}$ & 2.0045 & 2.0043 & 2.0040 & 2.0045 & 2.0043 & 2.0045 & 2.0028 \\
\hline $\mathrm{E}_{\mathrm{C}-}-\mathrm{E}_{\mathrm{i}, \mathrm{eV}}$ & \multicolumn{3}{|c|}{1.84} & \multicolumn{3}{c|}{$\mathrm{V}_{\mathrm{C}}^{0 /+}$} & 1.79 \\
\hline Model & \multicolumn{3}{|c|}{$\mathrm{V}_{\mathrm{C}}^{0 /+}$} & \multicolumn{3}{c|}{$\mathrm{C}_{\mathrm{Si}} \mathrm{V}_{\mathrm{C}}^{0 /+}$} \\
\hline
\end{tabular}

Table 6. Spin-Hamiltonian parameters, energy levels and electronic models of the thermally stable deep intrinsic defects with $\mathrm{S}=1 / 2$ measured in HPSI $6 \mathrm{H}-\mathrm{SiC}$ samples at $\mathrm{T}=77 \mathrm{~K}$. For comparison, the literature data for Ky center were taken after (Bratus et al., 2005). 
As seen from Table 6 the EPR parameters of the PP defect are consistent with those of the $\mathrm{P}_{1}$ defect (see Table 4) and SI-5 center observed in HPSI 4H-SiC (Son et al., 2004) and electron irradiated n-type 4H-SiC at $77 \mathrm{~K}$ (a. Umeda, et al., 2004; a. Umeda et al., 2006). Therefore, similar to the $\mathrm{P}_{1}$ defect, the PP defect was attributed to the pair $\left(\mathrm{C}_{\mathrm{Si}} \mathrm{V}_{\mathrm{C}}^{0 /+}\right)$ in the positive charge state, which was previously found in p-type $4 \mathrm{H} \mathrm{SiC}$ with the energy level closed to the $\mathrm{V}_{\mathrm{C}}^{+}$(Umeda et al., 2007).

\section{Kinetic properties of the photosensitive impurities and defects in HPSI SiC}

4.1. Thermally stimulated charge carrier trapping and transfer process in HPSI $4 \mathrm{H}-\mathrm{SiC}$ As already mentioned in Sect. 3.2, the lifetime of the nonequilibrium charge carriers trapped into the donor and acceptor levels of nitrogen and boron in HPSI $4 \mathrm{H}-\mathrm{SiC}$ is very large (on the order of $30 \mathrm{~h}$ and longer) and the recombination rate of the photo-excited carriers is very small. The recombination between nonequilibrium charge carriers is impeded by the intercenter charge transfer process occurred in HPSI $4 \mathrm{H}-\mathrm{SiC}$ in the dark after termination of photo excitation.

As was shown in Fig. 4, in the dark, after termination of photo excitation, charge carrier transfer from the shallow nitrogen donor to a deep $P_{1}$ and $P_{2}$ defect centers lying $1.15 \mathrm{eV}$ below the conduction band bottom in HPSI $4 \mathrm{H}-\mathrm{SiC}$ samples and identified as $\left(\mathrm{C}_{\mathrm{Si}} \mathrm{V}_{\mathrm{C}}^{0 /-}\right)$, $\mathrm{V}_{\mathrm{Si}}^{3-}$, respectively. The efficiency of this electron transfer does not depend on the concentration of the nitrogen donor but is activated with increasing concentration of the deep donor centers, as the Fermi level approaches the band gap center. Studies of the thermally stimulated evolution of the photo-EPR spectra in the dark showed that, as the temperature increases, the nonequilibrium charge carriers, rather than becoming excited into the conduction band, are trapped into deep levels near which the Fermi quasi-level is localized at this temperature. As seen from Fig. 7, within $26 \mathrm{~h}$ after photo excitation by interband light has been terminated, EPR signals of boron and $\mathrm{P}_{1}, \mathrm{P}_{2}$ centers appear in the EPR spectrum obtained at $T=77 \mathrm{~K}$. As the temperature increases to $106 \mathrm{~K}$, the EPR signal intensity from boron and the $\mathrm{P}_{1}, \mathrm{P}_{2}$ centers decays, which suggests that nonequilibrium charge carriers are released from the trapping levels. Now, as the temperature decreases, a single signal of a trapping center of unknown nature with $\mathrm{g}=2.0048$, which is labeled in Fig. 7 by the letter L, appears in the EPR spectrum.

This means that nonequilibrium charge carriers detrapped from leaving the level of the $\mathrm{P}_{1}$, $\mathrm{P}_{2}$ centers, rather than being ionized into the conduction band, become trapped with decreasing temperature into another, deeper level, close to which the Fermi quasi-level at this temperature is located. If we heat the sample again to $140 \mathrm{~K}$, and reduce the temperature subsequently to $85 \mathrm{~K}$, the charge carriers will be released from the L center at the high temperature, and then trapped again at a low temperature into the level of the $X_{c, h}$ defect, which lies deeper in the band gap than the L center.

Because the nonequilibrium charge carrier transfer occurs within a narrow temperature interval, it appears only natural to assume that the levels of the $P_{1}, P_{2}, L$, and $X_{c, h}$ trapping centers are spaced from one another by an energy on the order of $\Delta \mathrm{T}=140-$ $107 \mathrm{~K}=33 \mathrm{~K}=2.85 \mathrm{meV}$. 


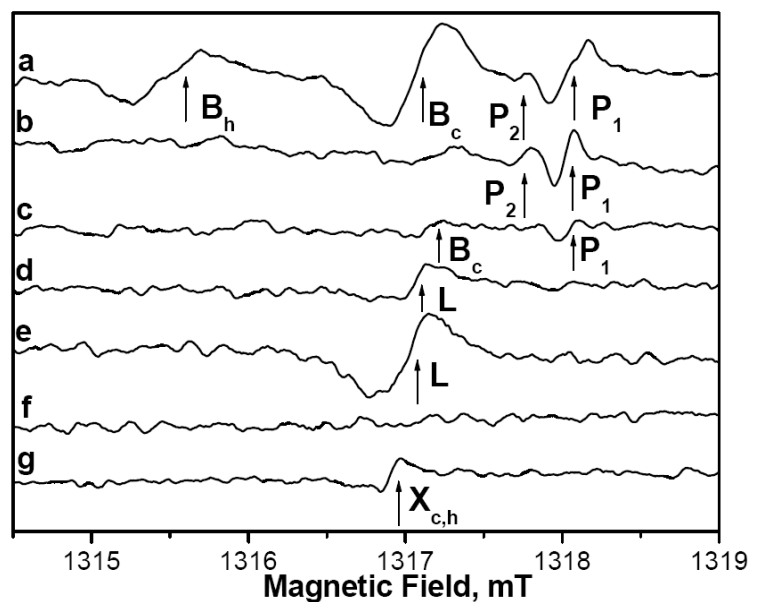

Fig. 7. Temperature-stimulated evolution of the photo-EPR spectra measured on HPSI $4 \mathrm{H}-$ $\mathrm{SiC}$ samples in the dark at $37 \mathrm{GHz}$. $\mathbf{B}_{0} \perp$ c. The spectrum was obtained $26 \mathrm{~h}$ (a) after termination of photo-excitation by interband light at $\mathrm{T}=77 \mathrm{~K}$ and $(\mathrm{b}-\mathrm{g})$ after a change in the temperature to (b) $\mathrm{T}=98.5 \mathrm{~K}$, (c) $\mathrm{T}=106 \mathrm{~K}$, (d) $\mathrm{T}=86 \mathrm{~K}$, (e) $\mathrm{T}=77 \mathrm{~K}$, (f) $\mathrm{T}=140 \mathrm{~K}$ and (g) $\mathrm{T}=88.5 \mathrm{~K}$. After (a. Savchenko et al., 2009).

Thus, within the temperature interval from $77 \mathrm{~K}$ to $140 \mathrm{~K}$, nonequilibrium charge carriers undergo thermally stimulated cascade transfer from the nitrogen donor level into three closely lying trapping centers in the band gap.

As the temperature decreases, the Fermi quasi-levels will approach the band gap and valence band edges, thus increasing the probability of trapping of photo-induced electrons and holes by shallow donors and acceptors. This pattern of the behavior of the Fermi quasilevels is corroborated by the low-temperature transformation of the photo-EPR spectra in HPSI 4H-SiC samples shown in Fig. 8.

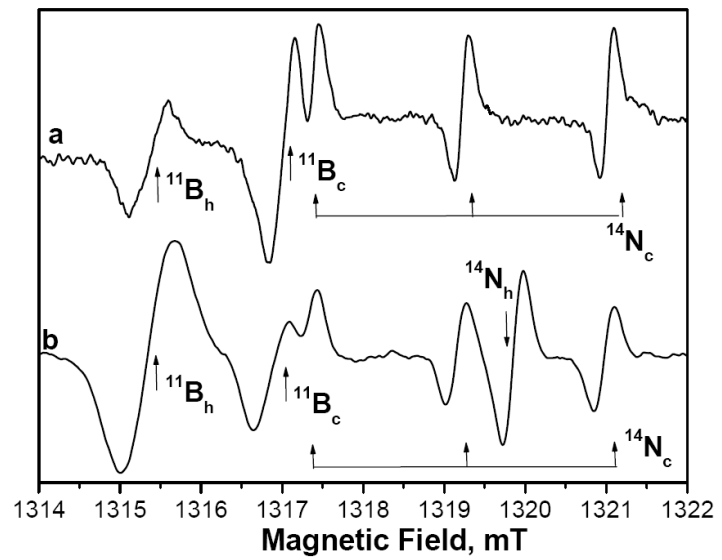

Fig. 8. EPR spectra observed in HPSI $4 \mathrm{H}-\mathrm{SiC}$ samples measured at $37 \mathrm{GHz}$ following by interband light. $\mathbf{B}_{0} \perp \mathbf{c}$. a $-\mathrm{T}=77, \mathrm{~b}-\mathrm{T}=50 \mathrm{~K}$. After (a. Savchenko et al., 2009). 
At $\mathrm{T}=50 \mathrm{~K}$, a signal appears in the photo-EPR spectrum due to nitrogen occupying the hexagonal $\left(\mathrm{N}_{\mathrm{h}}\right)$ position in the $4 \mathrm{H}-\mathrm{SiC}$ lattice and localized in a more shallow level in the band gap as compared to the $\mathrm{N}_{\mathrm{c}}$ position, see Table 3. Now, the ratio of EPR signals from boron in the $\mathrm{c}$ and $\mathrm{h}$ positions, 0.4 , becomes opposite to that observed at $\mathrm{T}=77 \mathrm{~K}$.

The latter observation suggests that, under the conditions where the Fermi hole quasi-level lies above the boron levels $(0.628 \mathrm{eV}$, see Table 3$)$ and their occupation is equally probable, the level of the boron in the $\mathrm{h}$ position is more shallow than that in the c position in the $4 \mathrm{H}$ $\mathrm{SiC}$ lattice and the concentration of paramagnetic centers in the $\mathrm{h}$ lattice positions is higher than that in the $\mathrm{c}$ positions.

\subsection{Decay kinetics of the PR of the nonequilibrium charge carriers trapped by the paramagnetic centers in HPSI 4H-SiC}

Figures 9 a,b display the decay with time of EPR line intensities of nitrogen and boron after termination of photo-excitation, which translate the variation with time of the concentration of nonequilibrium charge carriers trapped in the nitrogen and boron levels under photoexcitation.

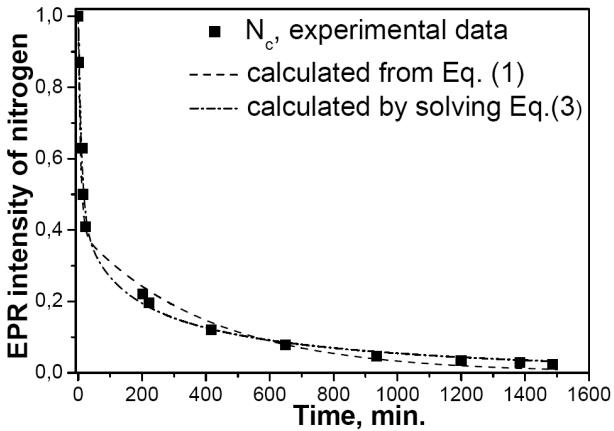

a

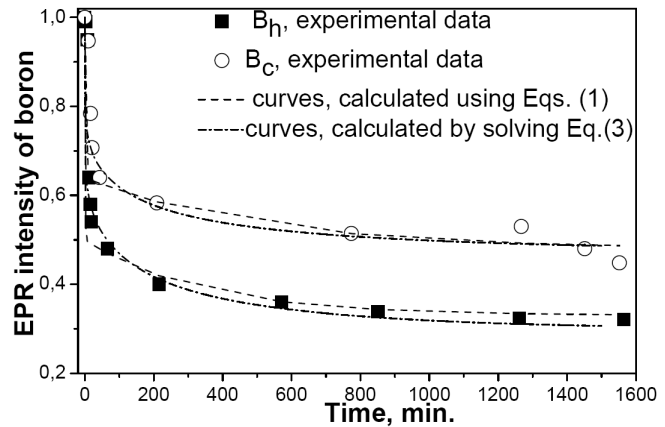

b

Fig. 9. Decay with time of the nitrogen (a) and boron (b) EPR signal intensity at $\mathrm{T}=77 \mathrm{~K}$ measured after termination of photo-excitation of the sample by interband light. After (a. Savchenko et al., 2009).

An analysis of the experimental curves yields the following relation for the decay of EPR signal intensities or concentrations of nonequilibrium charge carriers trapped by the paramagnetic centers:

$$
\begin{array}{r}
I_{D}=0.6 \exp \left(-\lambda_{1 D} t\right)+0.4 \exp \left(\lambda_{2 D} t\right) \\
I_{A c}=0.45+0.36 \exp \left(-\lambda_{1 A c} t\right)+0.16 \exp \left(-\lambda_{2 A c} t\right) \\
I_{A h}=0.33+0.5 \exp \left(-\lambda_{1 A h} t\right)+0.17 \exp \left(-\lambda_{2 A h} t\right)
\end{array}
$$

Here $I_{D}, I_{A c}, I_{A h}$ are the integrated intensities of EPR signals due to nitrogen, cubic boron, and hexagonal boron centers, respectively; $t$ is the time (in min); and $\lambda_{i}$ are the rates of exponential decay: $\lambda_{1 \mathrm{D}}=0.133 \mathrm{~min}^{-1}, \lambda_{2 \mathrm{D}}=0.0025 \mathrm{~min}^{-1}, \lambda_{1 \mathrm{Ac}}=0.48 \mathrm{~min}^{-1}, \lambda_{2 \mathrm{Ac}}=0.002 \mathrm{~min}^{-1}$, $\lambda_{1 \mathrm{Ah}}=1.1 \mathrm{~min}^{-1}$, and $\lambda_{2 \mathrm{Ah}}=0.003 \mathrm{~min}^{-1}$. 
The dashed curves in Figs. $9(a, b)$ plot the concentration decay of nonequilibrium charge carriers trapped in the nitrogen donors and boron acceptors, which were calculated from Eqs. (1). The experimental and theoretical curves demonstrate enough good agreement.

As seen from Figs. 9a and 9b, the decay curves of the nitrogen and boron EPR line intensities have slow and fast components. The slow components of the $\lambda_{2 \mathrm{D}}, \lambda_{2 \mathrm{Ac}}$ and $\lambda_{2 \mathrm{Ah}}$ decay curves have similar relaxation rates, which should be attributed to the effect of PR in the charge carrier, donor, and acceptor system.

The fast components of the decay curves for the boron acceptors $\left(\lambda_{1 \mathrm{Ac}}\right.$ and $\left.\lambda_{1 \mathrm{Ah}}\right)$ occupying positions $\mathrm{c}$ and $\mathrm{h}$ in the silicon carbide lattice have close relaxation rates, whereas the relaxation rate for the donors $\left(\lambda_{1 D}\right)$ is an order of magnitude smaller.

It should be noted that the higher relaxation rate components are seen at the smaller time scale indicating that the decay curves with time have super-exponential character.

The difference in the relaxation rates between the donors and acceptors may be due to the difference between their kinetic characteristics, as well as to the presence of traps for electrons and holes in the band gap, which brings about different residual EPR signal intensities from nitrogen and boron observed after termination of photo-excitation.

A comparison of the EPR spectra presented in Fig. 4 (curves b and c) suggests that after escaping from the nitrogen level the electrons become trapped into the level of the neighboring neutral trapping center, in this case, the $\mathrm{P}_{1}$ and $\mathrm{P}_{2}$ centers, where their lifetime is very long and reaches more than $1000 \mathrm{~min}$. after termination of photo-excitation. Thus, the rate of recombination between the trapped electrons and the holes trapped into boron levels is negligible, which is corroborated by the course of the slow component of the boron EPR signal decay.

Unfortunately, it was not possible to study the evolution with time of the concentration of nonequilibrium charge carriers trapped by the $P_{1}$ and $P_{2}$ defects because of their low EPR signal intensities.

\subsection{Decay kinetics of the PPC in HPSI 4H-SiC}

Fig. 10 plots the decay with time of persistent photocurrent after termination of photoexcitation with interband light, which was obtained at room temperature $(\mathrm{T}=300 \mathrm{~K})$ on HPSI 4H-SiC samples cut from the plate used to prepare samples for photo-EPR measurements (a. Kalabukhova et al., 2006). This permits a comparison of the data derived from the evolution with time of the PPC and PR of nonequilibrium concentration of the paramagnetic centers and their treatment in terms of the same processes occurring in HPSI $4 \mathrm{H}-\mathrm{SiC}$ samples under photo-excitation and after its termination.

The decay of photocurrent shown in Fig. 10 can be fitted by three exponentials

$$
I_{\text {curr }}=0,35 \exp \left(-\lambda_{1 e} t\right)+0,6 \exp \left(-\lambda_{2 e} t\right)+0,05 \exp \left(-\lambda_{3 e} t\right) \text {, }
$$

where $\lambda_{1 \mathrm{e}}=1.3 \mathrm{~min}^{-1}, \lambda_{2 \mathrm{e}}=0.125 \mathrm{~min}^{-1}$, and $\lambda_{3 \mathrm{e}}=0.002 \mathrm{~min}^{-1}$.

Examining Eqs. (1) and (2), we see that the decay of the photocurrent is described through the same relaxation rates as the acceptor and donor concentration decays, so that $\lambda_{1 \mathrm{e}} \approx \lambda_{1 \mathrm{Ah}}$, $\lambda_{2 \mathrm{e}} \approx \lambda_{1 \mathrm{D}}$ and $\lambda_{3 \mathrm{e}} \approx \lambda_{2 \mathrm{D}}$. 


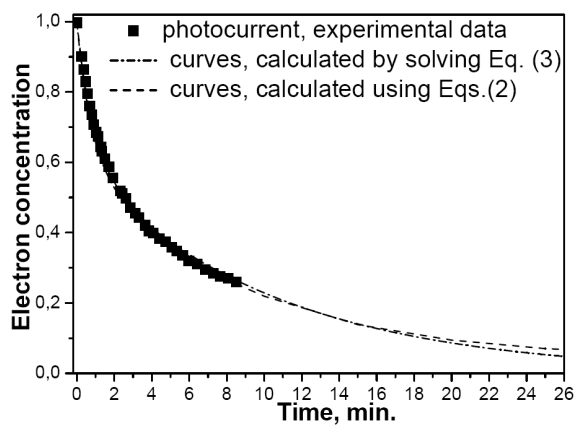

Fig. 10. Decay with time of persistent photocurrent in HPSI $4 \mathrm{H}-\mathrm{SiC}$ samples at $\mathrm{T}=300 \mathrm{~K}$ measured after termination of photo-excitation by interband light. After (a. Savchenko et al., 2009).

The empirical description of the PR and PPC decays cannot, however, be considered as satisfactory. It can give us only an idea about order-of-magnitude of the relaxation rates characterizing the processes in the donor and acceptor system while not providing any information about which of them are limiting.

A comprehensive theoretical analysis of the processes taking place in HPSI $4 \mathrm{H}-\mathrm{SiC}$ samples under photo-excitation and after its termination is proposed in Section 5.

\subsection{Electronic process describing the trapping and recombination process of the nonequilibrium charge carriers in HPSI $4 \mathrm{H}-\mathrm{SiC}$}

Fig. 11 schematically shows possible electronic transitions between the impurities and defects in HPSI $4 \mathrm{H}-\mathrm{SiC}$ samples under photo-excitation and after its termination.

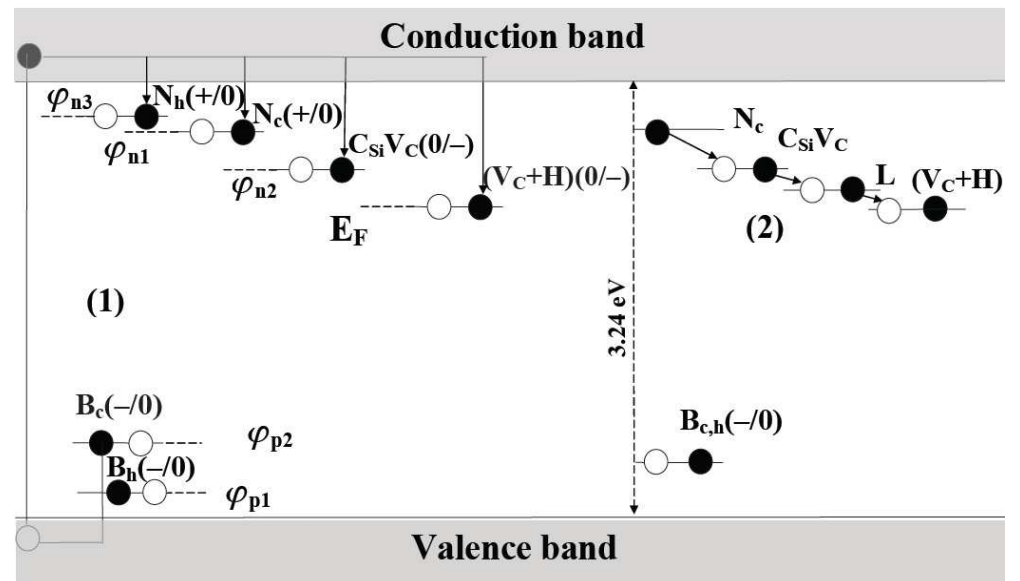

Fig. 11. Diagram of electronic transitions between impurities and defects in HPSI $4 \mathrm{H}-\mathrm{SiC}$ samples stimulated by photo-excitation with interband light and after its termination. $E_{\mathrm{F}}$ is the Fermi level in the dark; $\varphi_{\mathrm{n} 1}, \varphi_{\mathrm{n} 2}, \varphi_{\mathrm{n} 3}, \varphi_{\mathrm{p} 1}$, and $\varphi_{\mathrm{p} 2}$ are the Fermi quasi-levels under photoexcitation. $\mathrm{V}_{\mathrm{Si}}$ energy level was not shown on diagram due to its small concentration. 
Electronic transition 1 is involved in photo-excitation of HPSI $4 \mathrm{H}-\mathrm{SiC}$ samples by interband light. In this case, electrons are excited from the valence band into the conduction band, with their subsequent trapping from the conduction band into the nitrogen levels $\mathrm{N}_{c}$ and $\mathrm{N}_{h}$ and intrinsic defects including $\mathrm{C}_{\mathrm{Si}} \mathrm{V}_{\mathrm{C}}$ pair, $\mathrm{V}_{\mathrm{Si}},\left(\mathrm{V}_{\mathrm{C}}+\mathrm{H}\right)$ complex, and the holes, from the valence band into the boron levels $\mathrm{B}_{\mathrm{c}}$ and $\mathrm{B}_{\mathrm{h}}$.

Estimates of the concentrations of the nitrogen and boron centers derived from the integrated intensities of the EPR spectra showed them to be comparable in magnitude.

Electronic transition 2 relates to the processes occurring in HPSI $4 \mathrm{H}-\mathrm{SiC}$ samples after termination of their photo-excitation by interband light. Because the relaxation of EPR signals from boron acceptors and nitrogen donors is described by different exponentials, the probability of donor-acceptor recombination between nitrogen and boron is disregarded. The most probable appears to be cascade transfer of nonequilibrium charge carriers from nitrogen donors to deep donor trapping levels at the top of the band gap, where the charge carrier lifetime is very long.

\subsection{Electronic process describing the trapping and recombination process of the nonequilibrium charge carriers in SI $6 \mathrm{H}-\mathrm{SiC}$}

The electronic process describing the behavior of the photosensitive paramagnetic centers observed in $\mathrm{SI} 6 \mathrm{H}-\mathrm{SiC}$ under excitation with the light of different photon energies is shown in Fig. 12. The transitions 1-5 describe the excitation process of the samples by below band gap light. Transition 1 corresponds to electrons excited from valence band into $\mathrm{C}_{\mathrm{Si}} \mathrm{V}_{\mathrm{C}}$ pair. At the same time the holes in the valence band are captured by boron and carbon vacancy (transition 2,3), causing the corresponding appearance and disappearance of their EPR signals. Transitions 1 and 3 also describe charge transfer process between $V_{C}$ and $C_{S i} V_{C}$ pair. Transition 4 is the direct excitation of electrons to the $\mathrm{C}_{\mathrm{Si}} \mathrm{V}_{\mathrm{C}}$ pair followed by the capture of the valence band holes by boron.

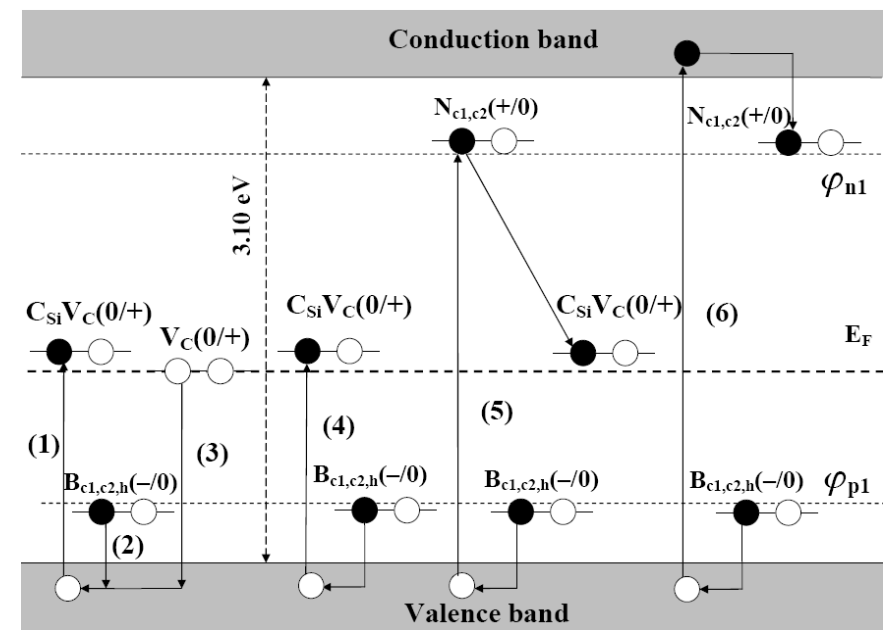

Fig. 12. Diagram of electronic transitions between impurities and defects in HPSI $6 \mathrm{H}-\mathrm{SiC}$ samples stimulated by photo-excitation with interband light and after its termination. $\mathrm{E}_{\mathrm{F}}$ is the Fermi level in the dark; $\varphi_{\mathrm{n} 1}$, and $\varphi_{\mathrm{p} 1}$, are the Fermi quasi-levels under photo-excitation. 
Transition 5 describes the process of boron and nitrogen neutralization, which could be induced by excitation of an electron from the valence band directly to an ionized donor, followed by capture of the hole by boron. In addition, the charge transfer process between nitrogen and $\mathrm{C}_{\mathrm{Si}} \mathrm{V}_{\mathrm{C}}$ pair is shown.

The illumination of the sample by above band gap (UV) light (transition 6) induces the neutralization of the shallow donors and acceptors and as a result the EPR spectra of nitrogen and boron are observed simultaneously in the EPR spectrum.

\section{Theory and comparison with experiment}

\subsection{Rate equations describing the electronic process occurring between impurities and defects in HPSI $4 \mathrm{H}-\mathrm{SiC}$ after termination of the photo-excitation}

In this chapter, the identification of the rate-limiting electronic processes shaping the behavior of PR and PPC has been presented for the HPSI 4H-SiC samples. To that end, we considered rate equations for the system of donors, acceptors, traps, and current charge carriers for the case where interband light is switched off and the transition to equilibrium state in the dark is studied.

By solving the rate equations and fitting them to the experimental curves displayed in Figs. 9, 10, we obtained kinetic characteristics of the photosensitive paramagnetic centers and the probabilities of the electronic and hole transitions illustrated in Fig. 11.

It should be noted that there is no influence of spin relaxation on the decay of the concentration of the paramagnetic centers observed in HP SI $4 \mathrm{H}-\mathrm{SiC}$ after termination of the photo-excitation because the steady-state saturation method has been used for the registration of the EPR signals.

Assuming interaction among the main nitrogen donor centers, boron acceptors, traps, and charge carriers to be the most efficient processes, we write rate equations for neutral paramagnetic donors $\mathrm{D}^{0}$, electrons $\mathrm{n}$, neutral paramagnetic boron centers $\mathrm{A}^{0}$, and holes $\mathrm{p}$. The concentration of neutral electron traps, which after trapping of electrons become negatively charged paramagnetic centers, is given by the charge neutrality condition $\mathrm{n}_{\mathrm{t}}^{0}=\mathrm{n}+\left(\mathrm{D}^{0}-\mathrm{A}^{0}\right)-\mathrm{p}-(\mathrm{D}-\mathrm{A})+\mathrm{n}_{\mathrm{t}}$ :

$$
\begin{aligned}
& \frac{\mathrm{dD}^{0}}{\mathrm{dt}}=-\left(\mathrm{w}_{\mathrm{i} \mathrm{D}^{0}}+\mathrm{f}_{\mathrm{Dt}} \mathrm{n}_{\mathrm{t}}^{0}+\mathrm{f}_{\mathrm{eD}} \mathrm{n}\right) \mathrm{D}^{0}+\left(\mathrm{f}_{\mathrm{eD}} \mathrm{D}+\mathrm{w}_{\mathrm{nD}}\right) \mathrm{n} ; \\
& \frac{\mathrm{dA}^{0}}{\mathrm{dt}}=-\left(\mathrm{w}_{\mathrm{iA}}-\mathrm{f}_{\mathrm{pA}}(\mathrm{D}-\mathrm{A})+\mathrm{f}_{\mathrm{pA}}\left(\mathrm{n}+\mathrm{D}^{0}-\mathrm{A}^{0}\right)\right) \mathrm{A}^{0}+\mathrm{f}_{\mathrm{pA}} \mathrm{Ap} \\
& \frac{\mathrm{dn}}{\mathrm{dt}}=\mathrm{N}_{\mathrm{ph}} \mathrm{S}-\left(\mathrm{f}_{\mathrm{eD}}\left(\mathrm{D}-\mathrm{D}^{0}\right)+\mathrm{f}_{\mathrm{et}} \mathrm{n}_{\mathrm{t}}^{0}\right) \mathrm{n}-\mathrm{f}_{\mathrm{ep}} \mathrm{np}+\mathrm{w}_{\mathrm{iD}} \mathrm{D}^{0}+\mathrm{w}_{\mathrm{it}}\left(\mathrm{n}_{\mathrm{t}}-\mathrm{n}_{\mathrm{t}}^{0}\right) ; \\
& \frac{\mathrm{dp}}{\mathrm{dt}}=\mathrm{N}_{\mathrm{ph}} \mathrm{S}+\mathrm{w}_{\mathrm{iA}} \mathrm{A}^{0}-\mathrm{p}\left(\mathrm{f}_{\mathrm{pA}}\left(\mathrm{A}-\mathrm{A}^{0}\right)+\mathrm{f}_{\mathrm{ep}} \mathrm{n}\right)
\end{aligned}
$$

Here, $\mathrm{n}$ and $\mathrm{p}$ are the concentrations of free electrons and holes, respectively; $\mathrm{D}^{0}, \mathrm{~A}^{0}$, and are the concentrations of neutral paramagnetic donors, acceptors, and neutral nonparamagnetic traps, respectively; $\mathrm{D}, \mathrm{A}$, and $\mathrm{n}_{\mathrm{t}}$ are the total concentrations of donors, acceptors, and traps, respectively; $\mathrm{D}^{+}(0)=\mathrm{D}-\mathrm{D}^{0}$ and $\mathrm{A}-(0)=\mathrm{A}-\mathrm{A}^{0}$ are the concentrations of ionized donors and acceptors, respectively, which are changed in the presence of the kinetic fluxes of electrons 
and holes; $\mathrm{f}_{\mathrm{ij}}=\sigma_{\mathrm{ij}} \mathrm{v}_{\mathrm{i}}$ is the flux of charge carriers i reaching the corresponding trapping center $\mathrm{j}$, where $\sigma_{\mathrm{eD}}$ and $\sigma_{\mathrm{pA}}$ are the cross sections of electron and hole trapping into the donor and acceptor levels, $\sigma_{\mathrm{ep}}$ is the cross section of the electron-hole recombination collision, and $\mathrm{v}_{\mathrm{i}}$ is the charge carrier velocity. The product of $f_{i j}$ by the concentration of particles gives the probability of leaving or arrival of particles from/to the level in the band gap; $\mathrm{N}_{\mathrm{ph}} \mathrm{S}$ is the nonequilibrium charge carrier generation rate $\left(\mathrm{N}_{\mathrm{ph}}\right.$ is the photon concentration); $\mathrm{w}_{\mathrm{iD}^{\circ}}$ and $\mathrm{w}_{\mathrm{iA}}{ }^{\circ}$ are the rates of ionization of nonequilibrium charge carriers from the levels of donors $\mathrm{D}^{0}$ and acceptors $\mathrm{A}^{0}$.

The transfer of charge carriers from a donor level to a lower-lying level of the trap closest to the donor is described by the probability. The probability $\mathrm{wnD}_{\mathrm{nD}}$ in the first equation of coupled equations (3) describes the increase in the concentration of neutral donors through electrons becoming trapped by an ionized donor not directly from the conduction band but via cascade transitions from one level to another in the band gap.

In the Eqs. (3) we have taken into account the recombination process, which is proportional to the product $n \cdot p$. The direct band-to-band recombination process is forbidden in our system because $4 \mathrm{H}-\mathrm{SiC}$ is a semiconductor with indirect band structure. However, if the traps capture of both the electrons and holes they will act as a recombination center. The efficiency of this process will be estimated from the comparison of solution of Eqs. (3) with the experimental curves.

\subsection{Rate parameters of the electronic process occurring in HPSI $4 \mathrm{H}-\mathrm{SiC}$ after termination of photo-excitation derived from the solution of the rate equations}

Experiments have shown that the evolution of the donor, acceptor, and charge carrier concentrations in the dark takes place with rates, which are equal in order of magnitude, and sometimes even in magnitude, for the different subsystems described by Eqs. (1) and (2). This suggests that the system may be considered closed.

The initial values for $\mathrm{n}, \mathrm{D}^{0}, \mathrm{~A}^{0}$, and $\mathrm{p}$ at time $\mathrm{t}=0$ after the termination of illumination were found as steady-state solutions of Eqs. (3) (i.e., for $t \rightarrow \infty$ all derivatives are zero) for the case of strong illumination, where the condition is satisfied $\mathrm{N}_{\mathrm{ph}} \mathrm{S} /\left(\mathrm{f}_{\mathrm{ep}} \mathrm{D}\right)>>$ D. These values are given by

$$
\mathbf{n}(\mathbf{0})=\mathbf{p}(\mathbf{0})=\mathrm{G}_{\mathrm{S}}, \mathrm{A}^{0}(0)=\frac{\mathrm{G}_{\mathrm{S}}}{\mathrm{r}_{\mathrm{A}}+\mathrm{G}_{\mathrm{S}} / \mathrm{A}}, \mathrm{D}^{0}(0)=\frac{\mathrm{G}_{\mathrm{S}}+\mathrm{r}_{\mathrm{t}} \cdot \mathrm{A}^{0}(0)-\mathrm{r}_{\mathrm{t}} \cdot \Delta}{\mathrm{r}_{\mathrm{D}}+\mathrm{r}_{\mathrm{t}}+\mathrm{G}_{\mathrm{S}} / \mathrm{D}},
$$

where $\mathrm{G}_{\mathrm{S}}=\left(\mathrm{N}_{\mathrm{ph}} \mathrm{S} / \mathrm{f}_{\mathrm{ep}}\right)^{1 / 2}, \mathrm{r}_{\mathrm{D}}=\mathrm{w}_{\mathrm{iD}} /\left(\mathrm{f}_{\mathrm{eD}} \mathrm{D}\right), \mathrm{r}_{\mathrm{A}}=\mathrm{w}_{\mathrm{iA}} /\left(\mathrm{f}_{\mathrm{pA}} \mathrm{A}\right), \mathrm{r}_{\mathrm{t}}=\mathrm{f}_{\mathrm{et}} / \mathrm{f}_{\mathrm{eD}}$, and $\Delta=\mathrm{n}_{\mathrm{t}}+\mathrm{A}-\mathrm{D}$. The equilibrium values of the variables in the dark are obtained as steady-state solutions of Eqs. (3) for $\mathrm{N}_{\mathrm{ph}} \mathrm{S}=0$ :

$$
\begin{gathered}
\mathbf{n}_{\text {eq }}=0 ; D_{\text {eq }}^{0}=0, \mathbf{p}_{\text {eq }}=\mathbf{A}(\mathbf{A}-\mathrm{D}) / \mathrm{D} ; \mathrm{A}_{\text {eq }}^{0}=\mathrm{r}_{\mathrm{A}}^{-1} \mathrm{~A}(\mathrm{~A}-\mathrm{D}) / \mathrm{D}, \text { for } \mathbf{A}>\mathbf{D} \\
\mathrm{n}_{\mathrm{eq}}=\mathrm{n}_{\mathrm{t}} \sqrt{\mathrm{w}_{\mathrm{it}} /\left(\mathrm{n}_{\mathrm{t}} \cdot \mathrm{f}_{\mathrm{Dt}}+\mathrm{n}_{\mathrm{t}} \cdot \mathrm{f}_{\mathrm{et}}\right)} ; \mathbf{D}_{\text {eq }}=0 ; \mathbf{A}_{\text {eq }}=\mathbf{0} ; \mathbf{p}_{\text {eq }}=\mathbf{0} \text {, for } \mathbf{A}<\mathrm{D} .
\end{gathered}
$$

The right-hand side of Eqs. (3) contains terms quadratic in the donor and acceptor concentrations. Because the samples are high resistive, all the variables $n, D^{0}, A^{0}<<(D+A)$. 
It would seem that one could now neglect the quadratic terms and solve the linear differential equations. In this case, we would obtain simple analytic solutions for system (3) in the form of a linear combination of exponentials.

While this approximate solution would not be valid for the total range of relaxation times, it would be acceptable for the interval within which the fastest-decaying quantities have completed their relaxation.

It can be shown that, in this case, a pair of coupled equations for acceptors and holes has one of the solutions of the secular equation for the decay rates, which is equal to zero. This relates to an extremely slow decay of the acceptor concentration. Indeed, in an experiment, one observes a considerable slowing down of the acceptor EPR signal $1000 \mathrm{~min}$ after the switching off the light. In this case, the residual acceptor concentration differs from the equilibrium value $\mathrm{A}_{\mathrm{eq}}^{0}=0$ and the evolution of the EPR signal with time cannot be fitted with one exponential. Moreover, when we neglect quadratic terms, we actually disregard the electron-hole recombination processes.

All this suggests the importance of the quadratic terms on the right-hand side of Eqs. (3), which are actually responsible for the fast EPR signal intensity decay. For this reason, the coupled differential equations (3) were solved numerically with inclusion of all the quadratic terms by the finite difference method. In this approach, we increase the time by such a small increment $\Delta \mathrm{t}$ at which, in the Taylor expansion of the time dependent functions $\mathrm{n}(\mathrm{t}), \mathrm{D}^{0}(\mathrm{t}), \mathrm{A}^{0}(\mathrm{t})$, and $\mathrm{p}(\mathrm{t})$, one may restrict oneself to three first terms, including the term with $(\Delta t)^{2}$. The values of $n(t), D^{0}(t), A^{0}(t)$, and $p(t)$, as well as their first and second derivatives with respect to time, were assumed to be equal to the values reached at the preceding instant of time. The value of the first derivative was calculated as the right-hand side of rate equations (3), and that of the second derivative, as the derivative of the righthand side of Eqs. (3). The solutions for the variables at the time $t+\Delta t$ thus obtained are substituted into the rate coefficients of Eqs. (3), and the procedure is repeated until the relaxation is complete.

Thus, the finite difference method chosen for solution of rate equations (3) has provided explanation for the existence of additional fast processes as due to the presence in the rate coefficients of time-varying terms. Graphic plots of the solutions obtained were fitted to the experimental curves shown in Figs. 9, 10.

The parameters of the rate equations were varied until the theoretical graphs matched fully the experimental EPR decay curves. The dash-dotted lines in Figs. 9, 10 plot the numerical solutions of Eqs. (3) for values of the rate coefficients which agree with experimental curves and are listed in the Table 7.

As can be seen from Table 7 , numerical values of the rate parameters $f_{e D} D, f_{p A} A$ and $f_{D t} n_{t}$ obtained from PPC data at $300 \mathrm{~K}$ and from the decay of EPR signal intensities of nitrogen and boron centers at $77 \mathrm{~K}$ are close to each other which indicates that the probability for charge carriers to be trapped by ionized nitrogen, boron centers and traps does not depend on the temperature.

On the contrary, the numerical values of the $\mathrm{w}_{\mathrm{iD}}, \mathrm{w}_{\mathrm{iA}}$ describing the rates of ionization of charge carriers from the levels of donors $\mathrm{D}^{0}$ and acceptors $\mathrm{A}^{0}$ exponentially depend on the temperature: $\exp \left(\mathrm{E}_{\mathrm{i}} / \mathrm{kT}\right)$, where $\mathrm{E}_{\mathrm{i}}$ is the energy ionization of the trapping centers. 


\begin{tabular}{|c|c|c|c|c|}
\hline \multirow{2}{*}{ Parameter } & PPC & \multicolumn{3}{|c|}{ Decay of EPR signal intensity, $\mathrm{T}=77 \mathrm{~K}$} \\
\cline { 2 - 5 } & $\mathrm{T}=300 \mathrm{~K}$ & $\mathrm{~N}_{\mathrm{c}}$ & $\mathrm{B}_{\mathrm{c}}$ & $\mathrm{B}_{\mathrm{h}}$ \\
\hline $\mathrm{f}_{\mathrm{eD}} \mathrm{D}, \mathrm{min}^{-1}$ & 0.0045 & 0.0033 & 0.0033 & 0.0033 \\
\hline $\mathrm{W}_{\mathrm{iD}}, \mathrm{min}^{-1}$ & $1.35 \cdot 10^{-3}$ & $1.65 \cdot 10^{-4}$ & $1.65 \cdot 10^{-4}$ & $1.65 \cdot 10^{-4}$ \\
\hline $\mathrm{f}_{\mathrm{pA}} \mathrm{A}, \mathrm{min}^{-1}$ & 0.017 & 0.02 & 0.02 & 0.017 \\
\hline $\mathrm{W}_{\mathrm{iA}}, \mathrm{min}^{-1}$ & 0.52 & 0.072 & 0.072 & 0.06 \\
\hline $\mathrm{f}_{\mathrm{ep}} \mathrm{D}, \mathrm{min}^{-1}$ & 0.044 & 0.014 & 0.014 & 0.014 \\
\hline $\mathrm{f}_{\mathrm{Dt}} \mathrm{n}_{\mathrm{t}}, \mathrm{min}^{-1}$ & 0.13 & 0.16 & 0.16 & 0.16 \\
\hline
\end{tabular}

Table 7. Rate parameters of the processes of recombination, trapping, and ionization of nonequilibrium charge carriers occurring in HPSI $4 \mathrm{H}-\mathrm{SiC}$ samples after termination of photo-excitation.

\subsection{Kinetic characteristics of the photosensitive impurities and defects in HPSI $4 \mathrm{H}-\mathrm{SiC}$}

A comparison of the relaxation parameters of the donor, acceptor, trap, and charge carrier system listed in Table 7 with the relaxation times obtained through an empirical description of the experiment reveals that the rates of exponential decay $\mathrm{I}(\mathrm{T})$ derived for acceptors from relation (1) $\left(\lambda_{1 \mathrm{Ac}}=0.48 \mathrm{~min}^{-1}\right.$ and $\left.\lambda_{1 \mathrm{Ah}}=1.1 \mathrm{~min}^{-1}\right)$ are characteristic of none of the recombination, trapping, and ionization of nonequilibrium charge carrier processes occurring in HPSI $4 \mathrm{H}-\mathrm{SiC}$ samples after termination of photo-excitation. The reason for this lies in that the law by which the integrated EPR signal intensities vary, rather than being described by a sum of exponentials, is actually superexponential because, for times $\mathrm{t}<10 \mathrm{~min}$, the rate coefficients for system (3) vary exponentially with time.

As seen from Table 7, the probability for an electron to be trapped from the conduction band by an ionized nitrogen donor, $\mathrm{f}_{\mathrm{eD}} \mathrm{D}$, which enters the first and third equations of system (3) and can be determined with a fairly high confidence, turned out to be small. On the other hand, in the course of solving the coupled equations, it was established that the increase of the concentration of neutral donors $\mathrm{D}^{0}$ should take place with an order-of-magnitude higher probability than $\mathrm{f}_{\mathrm{eD}} \mathrm{D}$. Therefore, we added to the second term of the first equation of (3) the term $\mathrm{W}_{\mathrm{nD}}$ which accounts for the probability of multi-step transitions of nonequilibrium charge carriers between levels in the band gap. This probability was found to be $\mathrm{W}_{\mathrm{nD}}=0.0117 \mathrm{~min}^{-1}$.

As seen from Fig. 11, in addition to ionization of the neutral nitrogen donor, there is also a possibility of cascade transfer of nonequilibrium charge carriers from the nitrogen donor level to trapping centers, which can also affect the concentration of neutral donors. It is this process that is the fastest in the system under study, $f_{D t} n_{t}=0.16 \mathrm{~min}^{-1}$. The trap concentration $\mathrm{n}_{\mathrm{t}}$ is 0.4 of the donor concentration $\mathrm{D}$.

The data of the Table 7 suggest that the rate of electron-hole recombination $\mathrm{f}_{\mathrm{ep}} \mathrm{D}$ plays an equally important role in recovery of equilibrium concentrations of all the participants of the process, and that it is comparable in magnitude with the probability of hole trapping by an ionized boron acceptor. Recombination favors fast relaxation of the holes, but after the holes have relaxed, a further recovery of the neutral acceptor concentration involves the quadratic terms in the rate coefficients associated with the concentration of donors and free charge carriers. Relaxation of the latter is restricted by the very low probability of ionization of the nitrogen neutral donor, $\mathrm{w}_{\mathrm{iD}}=1.65 \cdot 10^{-4} \mathrm{~min}^{-1}$. The slow hole relaxation, which sets in after the donors and electrons have recovered their equilibrium values, has a nearly constant 
value determined by the $\mathrm{w}_{\mathrm{iA}} /\left(\mathrm{f}_{\mathrm{pA}} \mathrm{A}\right)$ ratio only. The larger this ratio, the smaller is the final level of EPR signal intensities due to the boron acceptors $I_{A c}$ and $I_{A h}$ observed after termination of photo-excitation. As seen from the Table 7, the probability for a hole to be trapped from the valence band into an ionized boron acceptor is higher by an order of magnitude than that for an electron to be trapped from the conduction band by an ionized nitrogen donor. Interestingly, the probability of direct hole trapping from the valence band by an ionized acceptor $B_{c}$ was found to be higher than that by an ionized acceptor $B_{h}$. This corroborates the data derived from the temperature dependence of photo-EPR spectra, which suggest that the boron level in the position $\mathrm{B}_{\mathrm{h}}$ is more shallow than that in $\mathrm{B}_{\mathrm{c}}$.

\section{Conclusions}

In this chapter the identification and kinetic properties of the photosensitive paramagnetic centers observed in HPSI $4 \mathrm{H}$ and $6 \mathrm{H}-\mathrm{SiC}$ under photo-excitation and after its termination have been described. The HPSI $4 \mathrm{H}$ and $6 \mathrm{H}-\mathrm{SiC}$ samples were shown to have four photosensitive paramagnetic centers, which can be photo-excited into a paramagnetic state and a nonparamagnetic state. Two of them are the well-known nitrogen and boron impurities, and the other two are thermally stable intrinsic defects with $S=1 / 2$, labeled $X$ and $\mathrm{P}_{1}, \mathrm{P}_{2}$ in $4 \mathrm{H} \mathrm{SiC}$ and $X X$ and $\mathrm{PP}$ in $6 \mathrm{H} \mathrm{SiC}$. The $X$ and $X X, \mathrm{P}_{1}$ and PP defects have similar g-tensors and symmetry features, respectively. The EPR spectrum of $X$ and $X X$ defect was observed in the dark while EPR signals due to $\mathrm{P}_{1}, \mathrm{P}_{2}$ and PP defects appeared in the EPR spectrum of HPSI $4 \mathrm{H}$ and $6 \mathrm{H}-\mathrm{SiC}$ samples under photo-excitation.

The EPR parameters and ligand HF structure of the $X$ defect residing at two inequivalent lattice sites $\left(X_{h}\right.$ and $\left.X_{c}\right)$ with ionization levels 1.36 and $1.26 \mathrm{eV}$ below the conduction band were found to be in excellent agreement with those of carbon vacancy $V_{C}^{0 /+}$, both at the $c$ and $\mathrm{h}$ lattice sites known as ID1, D2 centers in HPSI 4H SiC and E15, E16 centers in electron irradiated $4 \mathrm{H} \mathrm{SiC}$. However, a significant discrepancy in the intensity ratio of lines with the smallest HF splitting was found for $\mathrm{X}_{\mathrm{C}}$-defect, ID1 and E15 center and explained by the presence of the hydrogen in the vicinity of the carbon vacancy. This conclusion is supported by the ionization energy of $\mathrm{X}$-defect, which is in contrast to the $\mathrm{V}_{\mathrm{C}}^{0 /+}$ close to that calculated for $V_{C}$ with adjacent hydrogen $\left(V_{C}+H\right)$. Thus, the $X$-defect which shows the donor-like behavior, was assigned to the hydrogenated carbon vacancy $\left(V_{C}+H\right)^{0 /-}$ which occupies the $c$ and $\mathrm{h}$ positions in the $4 \mathrm{H}-\mathrm{SiC}$ lattice. In contrast to the $\mathrm{X}$ defect, the $\mathrm{XX}$ defect whose energy level is pinned in the lower half of the band gap $\left(E_{C}-1.84 \mathrm{eV}\right)$ and shows acceptor-like behavior was attributed to the $\mathrm{V}_{\mathrm{C}}^{0 /+}$ at three inequivalent positions.

The EPR parameters of the $\mathrm{P}_{1}$ defect which were observed in EPR spectrum of HPSI $4 \mathrm{H} \mathrm{SiC}$ under photo-excitation or due to the charge carrier transfer from the shallow nitrogen donor to a deep $\mathrm{P}_{1}$ defect center after termination of the photo-excitation was found to be coincided with those of SI-5 center observed in HPSI $4 \mathrm{H} \mathrm{SiC}$ and in electron irradiated ntype $4 \mathrm{H} \mathrm{SiC}$. Energy position of the $\mathrm{P}_{1}$ defect coincides with that of SI-5 center which amounts to $1.1 \mathrm{eV}$ below the conduction band and coincides with the ionization levels calculated from the first principles for the carbon antisite-vacancy pair in the negative charge state $\left(\mathrm{C}_{\mathrm{Si}} \mathrm{V}_{\mathrm{C}}^{0 /-}\right)$. Therefore, $\mathrm{C}_{\mathrm{Si}} \mathrm{V}_{\mathrm{C}}$ pair has been suggested as the most possible model for the $\mathrm{P}_{1}$ defect. 
By analogy with the $\mathrm{P}_{1}$ defect, the PP defect was also attributed to the carbon AV pair but in the positive charge state $\left(\mathrm{C}_{\mathrm{Si}} \mathrm{V}_{\mathrm{C}}^{0 /+}\right)$. The $\mathrm{P}_{2}$ EPR signal of small intensity with the isotropic gfactor similar to that observed for SI-11 center was tentatively attributed to the silicon vacancy in the negative charge state $\mathrm{V}_{\mathrm{Si}}^{3-}$.

The study of the kinetic properties of the photosensitive impurities and defects in HPSI $4 \mathrm{H}-$ $\mathrm{SiC}$ and $6 \mathrm{H}-\mathrm{SiC}$ has shown that the lifetime of the nonequilibrium charge carriers trapped into the donor and acceptor levels of nitrogen and boron is very large (on the order of $30 \mathrm{~h}$ and longer) and the recombination rate of the photo-excited carriers is very small. Such a PR of the photo-response after termination of photo-excitation was found to be accompanied by the PPC phenomenon. To identify the rate-limiting electronic processes shaping the behavior of PR and PPC in HPSI 4H-SiC the rate equations describing the processes of recombination, trapping, and ionization of nonequilibrium charge carriers bound dynamically to shallow donors and acceptors (nitrogen and boron), as well as of charge carrier transfer from the shallow nitrogen donor to deep traps, have been solved. A comparison of calculations with experimental data has revealed the following efficient electron processes responsible for the PR and PPC in HPSI 4H-SiC samples.

(1) Multi-step transitions of nonequilibrium charge carriers from the nitrogen donor levels to trapping centers, among which the aggregated $\left(\mathrm{C}_{\mathrm{Si}} \mathrm{V}_{\mathrm{C}}^{0 /-}\right)$ centers play the main role. It turned out that the probability of this process is an order of magnitude higher than that of electron trapping from the conduction band by an ionized nitrogen donor. The probability of electron transfer from nitrogen donors to neighboring traps makes the latter the fastest relaxation process in the system under consideration.

(2) Electron-hole recombination, whose rate plays an equally essential role in the recovery of equilibrium concentrations of all centers involved in the fast PR and PPC processes.

(3) Ionization of boron acceptors $\left(\mathrm{w}_{\mathrm{iA}}\right)$, as well as hole escape from, or arrival at the boron level $\left(\mathrm{f}_{\mathrm{pA}} \mathrm{A}\right)$. The ratio of probabilities of these processes, $\mathrm{w}_{\mathrm{iA}} /\left(\mathrm{f}_{\mathrm{pA}} \mathrm{A}\right)$, mediates the rate of slow relaxation of the holes trapped into the boron acceptor levels. The higher the boron acceptor ionization probability, the faster is the PR process.

\section{References}

Aradi, B.; Gali, A.; Deak, P.; Lowther, J.E.; Son, N.T.; Janzen, E. \& Choyke, W.J. (2001). Ab initio density-functional supercell calculations of hydrogen defects in cubic SiC. Physical Review B, Vol. 63, No. 24, June 2001, 245202-1-245202-18, ISSN 1098-0121

a. Bockstedte, M.; Heid, M. \& Pankratov, O. (2003). Signature of intrinsic defects in SiC: Ab initio calculations of hyperfine tensors. Physical Review B, Vol. 67, No. 19, May 2003, 193102-1-193102-4, ISSN 1098-0121

b. Bockstedte, M.; Mattausch, A. \& Pankratov, O. (2003). Ab initio study of the migration of intrinsic defects in 3C-SiC. Physical Review B, Vol. 68, No. 20, November 2003, 205201-1-205201-17, ISSN 1098-0121

Bockstedte, M.; Mattausch, A. \& Pankratov, O. (2004). Ab initio study of the annealing of vacancies and interstitials in cubic $\mathrm{SiC}$ : Vacancy-interstitial recombination and aggregation of carbon interstitials. Physical Review B, Vol. 69, No. 23, June 2004, 235202-1-23520213, ISSN 1098-0121 
Bockstedte, M.; Gali, A.; Umeda, T.; Son, N.T.; Isoya, J. \& Janzen, E. (2006). Signature of the Negative Carbon Vacancy-Antisite Complex. Materials Science Forum, Vol. 527-529, October 2006, 539-542, ISSN 0255-5476

Bratus, V.Ya.; Petrenko, T.T.; Okulov, S.M. \& Petrenko, T.L. (2005). Positively charged carbon vacancy in three inequivalent lattice sites of $6 \mathrm{H}-\mathrm{SiC}$ : Combined EPR and density functional theory study. Physical Review B, Vol. 71, No. 12, March 2005, 125202-1-125202-22, ISSN 1098-0121

Carlsson, P.; Son, N.T.; Umeda, T.; Isoya, J. \& Janzen, E. (2007). Deep Acceptor Levels of the Carbon Vacancy-Carbon Antisite Pairs in 4H-SiC. Materials Science Forum, Vol. 556557, September 2007, 449-452, ISSN 0255-5476

Dissanayake, A.S.; Huang, S.X.; Jiang, H.X. \& Lin, J.Y. (1991). Charge storage and persistent photoconductivity in a $\mathrm{CdS}_{0.5} \mathrm{Se}_{0.5}$ semiconductor alloy. Physical Review B, Vol. 44, No. 24, December 1991, 13343-13348, ISSN: 1098-0121

Dissanayake, A.S. \& Jiang, H.X. (1992). Lattice relaxed impurity and persistent photoconductivity in nitrogen doped 6H-SiC. Applied Physics Letters, Vol. 61, No. 17, October 1992, 2048-2050, ISSN 0003-6951

Evwaraye, A.O.; Smith S.R.; Mitchel W.C. \& Hobgood, H.McD. (1997). Boron acceptor levels in 6H-SiC bulk samples. Applied Physics Letters, Vol. 71, No. 9, September 1997, 1186-1188, ISSN 0003-6951

Evwaraye, A.O.; Smith, S.R. \& Mitchel, W.C. (1995). Persistent photoconductance in n-type 6HSiC. Journal of Applied Physics, Vol. 77, No. 9, May 1995, 4477-4481, ISSN 0021-8979

Evwaraye, A.O.; Smith, S.R. \& Mitchel, W.C. (1996). Shallow and deep levels in n-type 4HSiC. Journal of Applied Physics, Vol. 79, No. 10, May 1996, 7726-7730, ISSN 0021-8979

Gali, A.; Deak, P.; Son, N.T.; Janzen, E.; von Bardeleben, H.J., Monge, Jean-Louis (2003). Calculation of Hyperfine Constants of Defects in $4 \mathrm{H}$ SiC. Materials Science Forum, Vol. 433-436, September 2003, 511- 514, ISSN 0255-5476

Greulich-Weber, S. (1997). EPR and ENDOR Investigations of Shallow Impurities in SiC Polytypes. Physica status solidi (a), Vol. 162, No. 1, July 1997, 95-151, ISSN 1862-6300

Greulich-Weber, S.; Feege, F.; Kalabukhova, E.N.; Lukin, S.N.; Spaeth, J.-M. \& Adrian, F.J. (1998). EPR and ENDOR investigations of B acceptors in 3C-, 4H- and 6H-silicon carbide. Semiconductor Science and Technology, Vol. 13, No. 1, January 1998, 59-70, ISSN 0268-1242

Kakalis, J. \& Fritzsche, H. (1984). Persistent Photoconductivity in Doping-Modulated Amorphous Semiconductors. Physical Review Letters, Vol. 53, No. 16, October 1984, 1602-1605, ISSN 0031-9007

Kalabukhova, E.N.; Lukin, S.N.; Shanina, B.D. \& Mokhov, E.N. (1990). Influence of Ge and excess $\mathrm{Si}$ on the ESR spectrum of nitrogen donor states in 6H-SiC. Soviet Physics Solid State, Vol. 32, No. 3, Match 1990, 465-469, ISSN 0038-5654

Kalabukhova, E.N.; Lukin, S.N.; Saxler, A.; Mitchel, W.C.; Smith, S.R.; Solomon, J.S. \& Evwaraye, A.O. (2001). Photosensitive electron paramagnetic resonance spectra in semi-insulating 4H SiC crystals. Physical Review B, Vol. 64, No. 23, December 2001, 235202-1-235202-4, ISSN: 1098-0121

Kalabukhova, E.N.; Lukin, S.N.; Savchenko, D.V.; Mitchel, W.C. \& Mitchell, W.D. (2004). Photo-EPR and Hall measurements on Undoped High Purity Semi-Insulating $4 \mathrm{H}-$ SiC Substrates. Materials Science Forum, Vol. 457-460, June 2004, 501-504, ISSN 02555476 
a. Kalabukhova, E.N.; Lukin, S.N.; Savchenko, D.V.; Sitnikov, A.A.; Mitchel, W.C.; Smith, S.R. \& Greulich-Weber, S. (2006) Trapping Recombination Process and Persistent Photoconductivity in Semi-Insulating 4H-SiC. Materials Science Forum, Vol. 527-529, October 2006, 563-566, ISSN 0255-5476

b. Kalabukhova, E.N.; Lukin, S.N.; Savchenko, D.V.; Mitchel, W.C.; Greulich-Weber, S.; Rauls, E. \& Gerstmann, U. (2006). Possible Role of Hydrogen within the So-Called X Center in Semi-Insulating 4H-SiC. Materials Science Forum, Vol. 527-529, October 2006, 559-562, ISSN: 0255-5476

Kalabukhova, E.N.; Lukin, S.N.; Savchenko, D.V.; $\quad$ Mitchel, W.C.; Greulich-Weber, S.; Gerstmann, U.; Pöppl, A.; Hoentsch, J.; Rauls, E.; Rozentzveig, Yu.; Mokhov, E.N.; Syväjärvi, M. \& Yakimova, R. (2007). EPR, ESE and Pulsed ENDOR Study of Nitrogen Related Centers in $4 \mathrm{H}-\mathrm{SiC}$ Wafers grown by Different Technologies. Materials Science Forum, Vol. 556-557, September 2007, 355-358, ISSN 0255-5476

Langhanki, B.; Greulich-Weber, S.; Spaeth, J.-M.; Markevich, V.P.; Clerjaud, B. \& Naud, C. (2001). Magnetic resonance and FTIR studies of shallow donor centers in hydrogenated Cz-silicon. Physica B, Vol. 308-310, December 2001, 253-256, ISSN 0921-4526

Lang, D.V. \& Logan, R.A. (1977). Large-Lattice-Relaxation Model for Persistent Photoconductivity in Compound Semiconductors. Physical Review Letters, Vol. 39, No. 10, September 1977, 635-639, ISSN 0031-9007

Litton, C.W. \& Reynolds, D.C. (1964). Double-Carrier Injection and Negative Resistance in CdS. Physical Review, Vol. 133, No. 2A, January 1964, A536-A541, ISSN 1050-2947

Macfarlane, P.J. \& Zvanut, M.E. (1999). Reduction and creation of paramagnetic centers on surfaces of three different polytypes of SiC. Journal of Vacuum Science ETechnology B, Vol. 17, No. 4, July 1999, 1627-1631, ISSN 1071-1023

Müller, St.G.; Brady, M.F.; Brixius, W.H.; Glass, R.C.; Hobgood, H.McD.; Jenny, J.R.; Leonard, R.T.; Malta, D.P.; Powell, A.R.; Tsvetkov, V.F.; Allen, S.T.; Palmour, J.W. \& Carter C.H.Jr. (2003). Sublimation-Grown Semi-Insulating SiC for High Frequency Devices. Materials Science Forum, Vol. 433-436, September 2003, 39-44, ISSN 02555476

Queisser, H.J. \& Theodorou, D.E. (1986). Decay kinetics of persistent photoconductivity in semiconductors. Physical Review B, Vol. 33, No. 6, March 1986, 4027-4033, ISSN 1098-0121

Rauls, E.; Frauenheim, Th.; Gali, A. \& Deak, P. (2003). Theoretical study of vacancy diffusion and vacancy-assisted clustering of antisites in SiC. Physical Review B, Vol. 68, No. 15, October 2003, 155208-1-155208-9, ISSN 1098-0121

Ryvkin, S.M. \& Shlimak, I.S. (1973). A doped highly compensated crystal semiconductor as a model of amorphous semiconductors. Physica status solidi (a), Vol. 16, No. 2, April 1973, 515-526, ISSN 1862-6300

Savchenko, D.V.; $\quad$ Kalabukhova, E.N.; $\quad$ Lukin, S.N.; $\quad$ Sudarshan, T.S.; Khlebnikov, Y.I.; Mitchel, W.C. \& Greulich-Weber, S. (2006). Intrinsic defects in high purity semiinsulating 6H SiC in Material Research Society Symposium Proceedings, Vol. 911, April, 2006, B05-07-1-B05-07-1-6, ISSN 02729172

Savchenko, D.V. \& Kalabukhova, E.N. (2009). EPR diagnostics of Defect and Impurity Distribution Homogeneity in Semi-Insulating 6H-SiC. Ukrainian Journal of Physics, Vol. 54, No. 6, June 2009, 605-610, ISSN 2071-0186 
a. Savchenko, D.V.; Shanina, B.D.; Lukin, S.N. \& Kalabukhova, E.N. (2009). Kinetics of the Behavior of Photosensitive Impurities and Defects in High-Purity Semi-Insulating Silicon Carbide. Physics of the Solid State, Vol. 51, No. 4, April 2009, 733-740, ISSN 1063-7834

b. Savchenko, D.V.; Kalabukhova, E.N.; Kiselev, V.S.; Hoentsch, J. \& Pöppl, A. (2009). Spincoupling and hyperfine interaction of the nitrogen donors in 6H-SiC. Physica Status Solidi B, Vol. 246, No. 8, August 2009, 1908-1914, ISSN 0370-1972

Shik, A.Ya. (1975). Photo-conductivity of randomly-inhomogeneous semiconductors. Soviet Physics - JETP, Vol. 41, No. 5, May 1975, 932-940, ISSN 0038-5646

Sheinkman, M.K. \& Shik, A.Ya. (1976). Long-time relaxations and residual conduction in semiconductors. Soviet Physics - Semiconductors, Vol. 10, No. 2, February 1976, 128143, ISSN 0038-5700

Sridhara, S.G.; Clemen, L.L; Devaty, R.P.; Choyke, W.J.; Larkin, D.J.; Kong, H.S.; Troffer, T. \& Pensl, G. (1998). Photoluminescence and transport studies of boron in $4 \mathrm{H} \mathrm{SiC}$. Journal of Applied Physics, Vol. 83, No. 12, June 1998, 7909-7919, ISSN 0021-8979

Son, N.T.; Magnusson, B.; Zolnai, Z.; Ellison, A. \& Janzen, E. (2004). Defects in high-purity semi-insulating SiC, Materials Science Forum, Vol. 457-460, June 2004, 437-442, ISSN 0255-5476

Son, N.T.; Magnusson, B. \& Janzen, E. (2002). Photoexcitation electron paramagnetic resonance studies of the carbon vacancy in $4 \mathrm{H}-\mathrm{SiC}$. Applied Physics Letters, Vol. 81, No. 21, November 2002, 3945-3947, ISSN 0003-6951

Suttrop, W.; Pensl, G.; Choyke, W.J.; Stein, R. \& Liebenzeder S. (1992). Hall effect and infrared absorption measurements on nitrogen donors in $6 \mathrm{H}$-silicon carbide. Journal of Applied Physics, Vol. 72, No. 8, October 1992, 3708-3713, ISSN 0021-8979

Torpo, L.; Marlo, M.; Staab T.E.M. \& Nieminen, R.M. (2001). Comprehensive ab initio study of properties of monovacancies and antisites in 4H-SiC. Journal of Physics: Condensed Matter, Vol. 13, No. 28, July 2001, 6203-6231, ISSN 0953-8984

a. Umeda, T.; Isoya, J.; Morishita, N.; Ohshima, T. \& Kamiya, T. (2004). EPR identification of two types of carbon vacancies in 4H-SiC. Physical Review B, Vol. 69, No. 12, March 2004, 121201-1-121201-4, ISSN 1098-0121

b. Umeda, T.; Isoya, J.; Morishita, N.; Ohshima, T.; Kamiya, T.; Gali, A.; Deak, P.; Son, N.T. \& Janzen, E. (2004). EPR and theoretical studies of positively charged carbon vacancy in 4H-SiC. Physical Review B, Vol. 70, No. 23, December 2004, 235212-1235212-6, ISSN 1098-0121

Umeda, T.; Ishitsuka, Y.; Isoya, J.; Son, N.T.; Janzen, E.; Morishita, N.; Ohshima, T. \& Itoh, H. (2005). EPR and theoretical studies of negatively charged carbon vacancy in $4 \mathrm{H}-\mathrm{SiC}$. Physical Review B, Vol. 71, No. 19, May 2005, 193202-1-193202-4, ISSN 1098-0121

a. Umeda, T.; Son, N.T.; Isoya, J.; Morishita, N.; Ohshima, T.; Itoh, H. \& Janzen, E. (2006). Electron paramagnetic resonance study of the HEI4/SI5 center in 4H-SiC. Materials Science Forum, Vol. 527-529, October 2006, 543-546, ISSN 0255-5476

b. Umeda, T.; Son, N.T.; Isoya, J.; Janzen, E.; Ohshima, T.; Morishita, N.; Itoh, H.; Gali. A. \& Bockstedte, M. (2006). Identification of the Carbon Antisite-Vacancy Pair in 4H-SiC. Physical Review Letters, Vol. 96, No. 14, April 2006, 145501-1-145501-4, ISSN 0031-9007

Umeda, T.; Morishita, N.; Ohshima, T.; Itoh, H. \& Isoya, J. (2007). Electron Paramagnetic Resonance Study of Carbon Antisite-vacancy pair in p-Type 4H-SiC. Materials Science Forum, Vols. 556-557, September 2007, 453-456, ISSN 0255-5476 


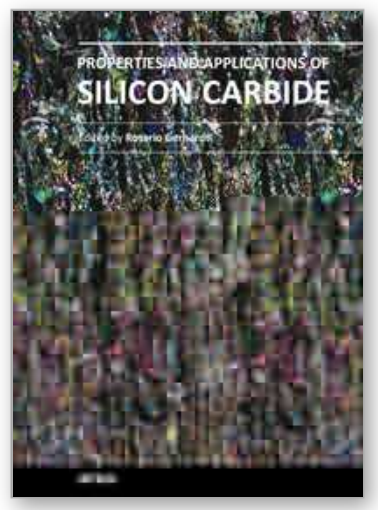

\author{
Properties and Applications of Silicon Carbide \\ Edited by Prof. Rosario Gerhardt
}

ISBN 978-953-307-201-2

Hard cover, 536 pages

Publisher InTech

Published online 04, April, 2011

Published in print edition April, 2011

In this book, we explore an eclectic mix of articles that highlight some new potential applications of $\mathrm{SiC}$ and different ways to achieve specific properties. Some articles describe well-established processing methods, while others highlight phase equilibria or machining methods. A resurgence of interest in the structural arena is evident, while new ways to utilize the interesting electromagnetic properties of SiC continue to increase.

\title{
How to reference
}

In order to correctly reference this scholarly work, feel free to copy and paste the following:

D. V. Savchenko, B. D. Shanina and E. N. Kalabukhova (2011). Identification and Kinetic Properties of the Photosensitive Impurities and Defects in High-Purity Semi-Insulating Silicon Carbide, Properties and Applications of Silicon Carbide, Prof. Rosario Gerhardt (Ed.), ISBN: 978-953-307-201-2, InTech, Available from: http://www.intechopen.com/books/properties-and-applications-of-silicon-carbide/identification-andkinetic-properties-of-the-photosensitive-impurities-and-defects-in-high-purity-se

\section{INTECH}

open science | open minds

\author{
InTech Europe \\ University Campus STeP Ri \\ Slavka Krautzeka 83/A \\ 51000 Rijeka, Croatia \\ Phone: +385 (51) 770447 \\ Fax: +385 (51) 686166 \\ www.intechopen.com
}

\author{
InTech China \\ Unit 405, Office Block, Hotel Equatorial Shanghai \\ No.65, Yan An Road (West), Shanghai, 200040, China \\ 中国上海市延安西路65号上海国际贵都大饭店办公楼 405 单元 \\ Phone: +86-21-62489820 \\ Fax: $+86-21-62489821$
}


(C) 2011 The Author(s). Licensee IntechOpen. This chapter is distributed under the terms of the Creative Commons Attribution-NonCommercialShareAlike-3.0 License, which permits use, distribution and reproduction for non-commercial purposes, provided the original is properly cited and derivative works building on this content are distributed under the same license. 